\title{
New Evidence in the Booming Field of Online Mindfulness: An Updated Meta-analysis of Randomized Controlled Trials
}

Marion Sommers-Spijkerman ${ }^{1}$, PhD; Judith Austin², MSc; Ernst Bohlmeijer ${ }^{2}, \mathrm{PhD}$; Wendy Pots ${ }^{2}, \mathrm{PhD}$

${ }^{1}$ Department of Rehabilitation, Physical Therapy Science and Sports, University Medical Center Utrecht, Utrecht, Netherlands

${ }^{2}$ Department of Psychology, Health and Technology, University of Twente, Enschede, Netherlands

\section{Corresponding Author:}

Marion Sommers-Spijkerman, $\mathrm{PhD}$

Department of Rehabilitation, Physical Therapy Science and Sports

University Medical Center Utrecht

Heidelberglaan 100

Utrecht, 3584 CX

Netherlands

Phone: 31652783025

Email: m.p.j.spijkerman-6@umcutrecht.nl

\section{Abstract}

Background: There is a need to regularly update the evidence base on the effectiveness of online mindfulness-based interventions (MBIs), especially considering how fast this field is growing and developing.

Objective: This study presents an updated meta-analysis of randomized controlled trials assessing the effects of online MBIs on mental health and the potential moderators of these effects.

Methods: We conducted a systematic literature search in PsycINFO, PubMed, and Web of Science up to December 4, 2020, and included 97 trials, totaling 125 comparisons. Pre-to-post and pre-to-follow-up between-group effect sizes (Hedges $g$ ) were calculated for depression, anxiety, stress, well-being, and mindfulness using a random effects model.

Results: The findings revealed statistically significant moderate pre-to-post effects on depression $(g=0.34,95 \%$ CI $0.18-0.50$; $P<.001)$, stress $(g=0.44,95 \%$ CI $0.32-0.55 ; P<.001)$, and mindfulness $(g=0.40,95 \%$ CI $0.30-0.50 ; P<.001)$ and small effects on anxiety $(g=0.26,95 \%$ CI $0.18-0.33 ; P<.001)$. For well-being, a significant small effect was found only when omitting outliers $(g=0.22,95 \%$ CI $0.15-0.29 ; P<.001)$ or low-quality studies $(g=0.26,95 \%$ CI $0.12-0.41 ; P<.001)$. Significant but small follow-up effects were found for depression $(g=0.25,95 \%$ CI $0.12-0.38)$ and anxiety $(g=0.23,95 \%$ CI $0.13-0.32)$. Subgroup analyses revealed that online MBIs resulted in higher effect sizes for stress when offered with guidance. In terms of stress and mindfulness, studies that used inactive control conditions yielded larger effects. For anxiety, populations with psychological symptoms had higher effect sizes. Adherence rates for the interventions ranged from $35 \%$ to $92 \%$, but most studies lacked clear definitions or cut-offs.

Conclusions: Our findings not only demonstrate that online MBIs are booming but also corroborate previous findings that online MBIs are beneficial for improving mental health outcomes in a broad range of populations. To advance the field of online MBIs, future trials should pay specific attention to methodological quality, adherence, and long-term follow-up measurements.

(JMIR Ment Health 2021;8(7):e28168) doi: 10.2196/28168

\section{KEYWORDS}

mindfulness; mental health; intervention; online; meta-analysis; mobile phone

\section{Introduction}

\section{Background}

In the 1970s, mindfulness was introduced as an intervention to tackle various psychological symptoms, such as stress, depression, and anxiety [1]. Mindfulness has been defined as the ability to be aware of bodily sensations, feelings, and

thoughts in the present moment with a curious and accepting attitude toward these experiences [2,3]. Since the 1970s, various mindfulness-based interventions (MBIs) have been developed. Mindfulness-Based Stress Reduction (MBSR) was originally developed for people with chronic pain to support them in coping with chronic stress [2,4]; Mindfulness-Based Cognitive Therapy (MBCT) was primarily developed for people with 
recurrent depression [5]; Dialectical Behavior Therapy was developed for cultivating emotion-regulation skills in people with borderline personality disorder [6]; and Acceptance and Commitment Therapy (ACT) was developed to increase psychological flexibility and reduce distress in people with various mental health problems [7]. Although these interventions vary in the use and duration of specific meditation exercises and in their theoretical and psycho-educational frameworks, they share a core focus on promoting awareness of sensations, emotions, and cognitions and the ability to not react to and identify with these bodily and mental events. Over the past decades, a large number of systematic reviews and meta-analyses have been conducted on the effectiveness of MBIs in various target groups [8-24]. Following a general trend in mental health care, MBIs are increasingly being delivered through the internet [25-27]. In 2015, we conducted a meta-analysis to examine the effectiveness of online MBIs published in 2016 [28]. In this meta-analysis, 15 randomized controlled trials (RCTs) totaling 17 comparisons of an online MBI with a control group were included. At postintervention, online MBIs outperformed controls on all outcomes. Short-term effects were promising and included enhanced well-being $(g=0.23)$, decreased depressive and anxiety symptomatology ( $g=0.29$ and $g=0.22$, respectively), reduced levels of stress $(g=0.51)$, and improved mindfulness $(g=0.32)$. Although these findings indicate that online MBIs have the potential to contribute toward improving mental health, the observed effects had to be interpreted with caution considering the limited number of included studies and the fact that many of the included RCTs were limited in scope, comparability, and methodological quality.

One year later, another meta-analysis focused on the same topic [10]. This meta-analysis included data collected until October 23, 2015, and showed considerable overlap with our meta-analysis; 21 RCTs were included in this study. The findings indicated significant pre-post improvements in anxiety, depression, and quality of life compared with the control conditions. Online MBIs were not found to be more effective than the comparison interventions.

In 2018, Sevilla-Llewellyn-Jones et al [9] performed a systematic review and meta-analysis on the effectiveness of online MBIs, specifically focusing on populations with diagnosed mental health problems. On the basis of 12 studies, online MBIs were found to significantly improve mindfulness skills in people with mental disorders. Furthermore, the findings demonstrated that online MBIs are effective in reducing depression and anxiety and improving quality of life in people with anxiety disorder, but not in people with depressive disorder.

In 2020, two more meta-analyses of technology-enabled and online MBIs were performed, focusing on stress management in the general population $(n=16)$ [29] and distress in clinical and nonclinical populations $(n=43)$ [30]. The findings demonstrated small-to-medium effects on stress, anxiety, depression, and mindfulness compared with active and nonactive control conditions $[29,30]$. As these reviews address a narrower target population [29] and scope of interventions [30] than our original meta-analysis, a comprehensive review of online MBIs is still lacking.

\section{Objectives}

Indeed, reviewing the literature from the past few years indicates that developments in the area of online mindfulness emphasize the need to regularly update the current evidence base. First, as anticipated, the field of online mindfulness is booming, as evidenced by dozens of studies that have been published since our previous meta-analysis. Incorporating these studies in a new meta-analysis would provide a more thorough assessment of the clinical and nonclinical utility of online MBIs and improve the power of moderation analyses. Second, we noticed a transformation in the types of online MBIs that are being delivered to users. At the time that our 2016 meta-analysis was conducted, MBSR and MBCT and derivatives from these interventions dominated the field. Since then, there has been a rapid increase in online ACT interventions, allowing a more robust assessment of this specific MBI. Third, it appears that the components of MBIs are increasingly mixed or hybrid, resulting in numerous MBIs that show considerable overlap and all seem to have a beneficial impact on mental health. It remains unclear whether mixtures of MBIs are equally effective in improving mental health. Fourth, not only is the content of today's online MBIs different from 5 years ago but also the delivery method is different. MBIs are increasingly delivered through smartphone apps instead of websites, increasing access modality and ease of usage. These developments spurred the desire to update and extend our 2016 meta-analysis to provide more robust evidence of the short-term and long-term effects of online MBIs, as well as the potential moderators of these effects.

\section{Methods}

This study was conducted according to the PRISMA (Preferred Reporting Items for Systematic Reviews and Meta-Analyses) guidelines [31]. The data collection and analysis procedures were similar to those used in our previous meta-analysis [28].

\section{Literature Search and Eligibility Criteria}

We searched the PsycINFO, PubMed, and Web of Science databases three times for RCTs published since 2015-that is, September 6, 2018; July 19, 2019 (by MSS and WP); and December 4, 2020 (by JA). The search strategy was identical to that used in our previous meta-analysis [28]. Search terms included synonyms, both in text words and Medical Subject Headings or thesaurus terms, for (1) mindfulness (eg, mindful* and meditation), (2) intervention (eg, intervention* and treatment ${ }^{*}$ ), (3) online (eg, e-health and Internet ${ }^{*}$ ), and (4) RCTs (eg, random* and trial). The search results were filtered for English-language journal articles. For complete search strings, we refer to our previous meta-analysis [28].

Trials were included when they met the following criteria:

- Examines the effectiveness of an MBI, that is, an intervention consisting of at least one guided or unguided session and a combination of psycho-education and more than one experiential exercise with a primary focus on enhancing mindfulness skills. Both mindfulness-only interventions (eg, MBSR and MBCT) and mindfulness-integrative interventions such as Dialectical 
Behavior Therapy, ACT, or Mindfulness-Based Compassionate Living were included. Derivatives and mixtures of programs were also eligible, provided that teaching mindfulness was at the core of the intervention.

- The MBI is delivered via the internet and can be followed on a computer or a mobile device such as a smartphone or tablet. Interventions that used a combination of face-to-face and online sessions were eligible when face-to-face sessions were limited to the introduction of the study.

- Use of a randomized controlled design with at least one experimental condition and one active or inactive control condition (ie, no treatment, usual care, or any active treatment other than the experimental intervention).

- Depressive symptoms, anxiety symptoms, stress, well-being, or mindfulness was measured pre- and postintervention, using a validated measure.

- Studies simultaneously using MBIs and non-MBIs were eligible for inclusion, provided that the design allowed us to distinguish the independent effects of the MBIs.

- The study population consisted of adults aged $\geq 18$ years. Both clinical (mental and physical disorders) and nonclinical samples (eg, students and community samples) were eligible.

- The reported findings allow the calculation of effect sizes, or the necessary data were made available by the authors. In addition, RCT protocols were screened for eligibility and included when the authors provided the necessary data.

The selection of studies took place in three phases: first, the review of titles; second, abstracts; and third, full texts. The selection was conducted independently by MSS, JA, and WP. Disagreements were resolved through discussion.

\section{Data Extraction}

Population, intervention, and methodological characteristics (Multimedia Appendix 1; Gao et al, unpublished data, 2021; [32-125]) as well as effect size data were extracted from the full-text papers by 3 raters (ie, MSS, JA, and WP) independently. When discrepancies occurred, these were resolved in the discussion. When the article provided insufficient information regarding the study characteristics, the authors were contacted.

\section{Quality Assessment}

Three raters (alternatingly, MSS, JA, and WP) independently assessed the methodological quality of each study using the same criteria as outlined in [28]. In brief, the criteria included (1) adequate sequence generation and allocation concealment; (2) blinding of main outcome assessments; (3) drop-out analysis; (4) adequate handling of missing data; (5) adequate sample size calculation; (6) comparability of experimental and control participants at baseline; and (7) diagnostic assessment of participants (only applicable for clinical samples). Raters coded each criterion as 1 (criterion is met) or 0 (criterion is not met). Disagreements between raters were resolved through discussion. Studies were scored between 0 and 7 points, with higher scores reflecting greater methodological quality. The methodological quality of each study was assessed as high (7 points), moderate (5-6 points), or low ( $\leq 4$ points).

\section{Data Analysis}

Meta-analytic procedures were performed using the Comprehensive Meta-Analysis software, version 2.2.064. Hedges $g$ effect sizes were calculated for (1) depressive symptoms, (2) anxiety symptoms, (3) stress, (4) well-being, and (5) mindfulness, using the same steps as reported in [28]. We calculated pre-to-post between-group effect sizes for all studies and pre-to-follow-up between-group effect sizes, thereby including only studies with a follow-up period of 1-3 months. Effect sizes reflect the number of SDs with which the online MBI group had more changed than the control condition between pre- and postmeasurement and pre- and follow-up measurement. Where available, intention-to-treat data were used to calculate effect sizes. If a study used more than one measure for the same outcome, we used the most valid instrument. However, in the case of well-being, we observed different dimensions of well-being (eg, a measure of emotional well-being and a measure of psychological well-being). In these cases, we extracted all relevant outcomes and computed the combined (average) effect sizes. When studies used more than one comparison condition, we used the strongest comparison to calculate the effect size. Following the study by Lipsey and Wilson [126], effect sizes from 0 to 0.32 were considered a small effect, 0.33 to 0.55 were considered a moderate effect, and 0.56 to 1.20 were considered a large effect.

Per outcome, forest plots of the pre-to-post effect sizes and pre-to-follow-up effect sizes were generated. A random effects model was used [127]. Meta-analyses were conducted, both including and excluding outliers. Outliers were identified through visual inspection of forest plots. In line with our previous meta-analysis [28], a study was deemed an outlier when its $95 \%$ CI fell outside the $95 \%$ CI of the overall mean effect size (on both sides). As a sensitivity analysis, meta-analyses were repeated, thereby omitting low-quality studies (including outliers).

The statistical procedures used to assess heterogeneity, publication bias, and moderators were identical to those used in our previous meta-analysis [28]. A priori, specified subgroup analyses were conducted to assess the differential effects of online MBIs based on (1) intervention type: MBSR, MBCT, ACT, or MBI (ie, mixture); (2) therapist guidance, with or without; (3) delivery mode: app or website; (4) population type: clinical or nonclinical; (5) type of symptoms: psychological, physical, or no symptoms; and (6) type of control: active (ie, treatment as usual, psycho-education, or other intervention) or inactive (ie, waitlist or no intervention). We conducted mixed effects analyses, thereby using a random effects model to pool studies within each subgroup and a fixed effect model to test whether effect sizes between subgroups significantly differed from one another. Only subgroups with five or more comparisons were reported. In addition to study quality and number of intervention sessions, mean age and proportion of females were included in the meta-regression analyses (mixed effects model and unrestricted maximum likelihood). Subgroup and meta-regression analyses were conducted, including outliers and only with pre-to-post data. 


\section{Results}

\section{Selection of Studies}

The first search yielded 1328 hits, the second yielded 532 hits, and the last yielded 1014 hits. A total of 928 duplicates were removed. After reviewing 1946 titles, 678 abstracts, and 207 full articles, we identified 82 new studies, totaling 105 comparisons, which were not included in our previous meta-analysis (Figure 1). In addition, 15 eligible studies, including 20 comparisons identified in our previous meta-analysis [28], were included. Accordingly, 97 RCTs, totaling 125 comparisons, were included in this meta-analysis.

Figure 1. Flowchart of the study selection process. MBI: mindfulness-based intervention; RCT: randomized controlled trial.

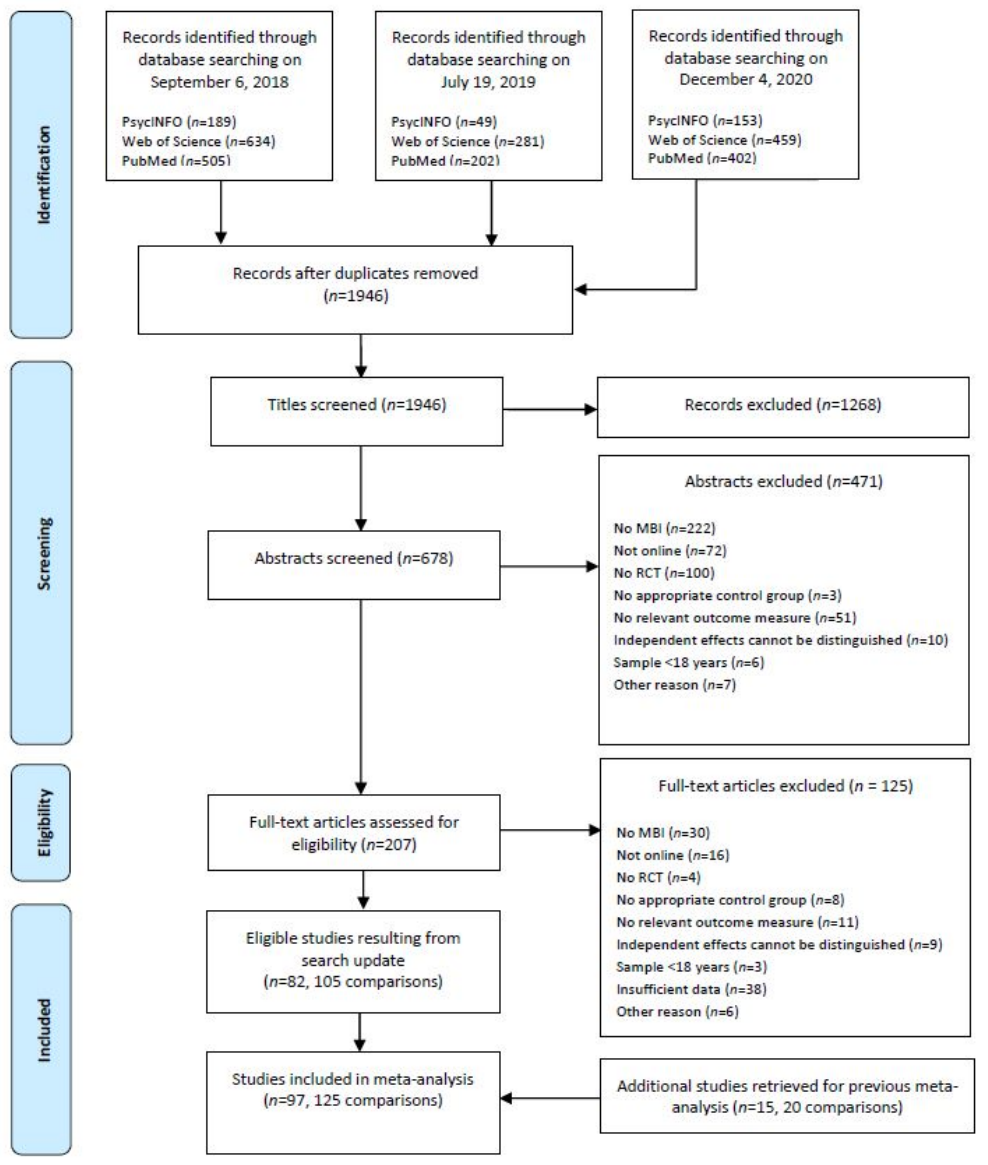

\section{Study Characteristics}

Although research on the effectiveness of online MBIs has been undertaken in 21 countries across the globe, nearly one-third of all studies were conducted in the United States $(n=31)$. Other countries in the top 5 included the United Kingdom, Sweden, the Netherlands, and China with 12, 10, 8, and 5 RCTs, respectively. Multimedia Appendix 1 shows the population, intervention, comparison, and outcome characteristics of all studies included in the meta-analysis.

The total study population consisted of 17,464 participants, with a mean age of 40 years. A total of 9066 participants were in the experimental condition and 7832 were in the control condition. There were large differences in sample sizes, ranging from 16 in a small-scale pilot RCT [32] to 2161 in a large-scale trial [33]. The proportion of women ranged from $41 \%$ to $100 \%$. Most studies were conducted among the general population, employees, or student samples (45/97, 46\% of studies). In 24 studies, online MBIs were targeted at populations with somatic illnesses, such as cancer $(\mathrm{n}=11)$ and chronic pain $(\mathrm{n}=7) ; 11$ studies were targeted at health care professionals $(n=4)$ and spousal or family caregivers $(n=7)$. The remaining 17 studies included samples with psychological symptomatology, with depressive and anxiety symptoms being the most prevalent $(n=12)$.

In $70.4 \%(88 / 125)$ of comparisons, a mindfulness-only intervention was used, with the most commonly studied intervention being MBSR $(n=21)$, followed by MBCT $(n=14)$, and a mixture or derivative of MBSR and MBCT and related exercises $(n=53)$. Mindfulness-integrative interventions were used in the remaining $29.6 \%$ (37/125) of comparisons, specifically ACT $(n=29)$, acceptance-based intervention $(n=3)$, compassion-based intervention $(n=4)$, and Mindfulness-Based Compassionate Living $(\mathrm{n}=1)$.

MBIs were mostly delivered through a website $(n=84)$, followed by an app $(n=27)$, virtual online classroom or videoconferencing software $(n=4)$, or a combination $(n=3)$. The number of online MBI sessions varied between 2 and 45. Sessions were used over a period of 10 days to 14 weeks. In $28.8 \%$ (36/125) of comparisons, online MBIs were provided with therapist guidance.

In $52 \%(65 / 125)$ of comparisons, the effectiveness of online MBIs was examined relative to a waitlist control $(n=61)$ or no 
intervention $(n=4)$ condition. An active control condition was used in $48 \%(60 / 125)$ of comparisons, including psycho-education $(n=13)$, an online discussion forum $(n=7)$, treatment as usual $(n=14)$, and an alternative intervention $(n=26$; eg, expressive writing, cognitive behavioral therapy, and behavioral activation).

Outcome measures for depressive symptoms, anxiety, stress, well-being, and mindfulness were administered in $82,70,54$, 48, and 67 comparisons, respectively; $44.3 \%$ (43/97) of studies reported not only pre- and postmeasurement but also follow-up measurements, with follow-up times ranging from 1 to 12 months.

\section{Adherence}

Although 70\% (68/97) of studies reported important information regarding adherence to the intervention (eg, time spent on the intervention, number of modules started, number of completed sessions, and daily meditation practice), only $23 \%$ (22/97) studies provided a definition or cut-off to determine adherence versus nonadherence. Using various definitions of adherence, these studies reported adherence rates ranging from $35 \%$ to $92 \%$.

\section{Quality of Included Studies}

Scores for methodological quality varied between 1 and 7 points (Multimedia Appendix 2; Gao, M, unpublished data, 2021; [32-125]). Of the 97 included studies, 33 (34\%) were considered low-quality studies; $66 \%$ (64/97) of the studies were rated as moderate $(n=53)$ or high $(n=11)$ quality. The results per quality criterion are shown in Figure 2.

Figure 2. Results of methodological quality assessment per criterion presented as percentages across all included studies.

Adequate sequence generation and allocation concealment

Blinding of main outcome assessments

Drop-out analysis
Intention-to-treat analysis
Adequate power analysis
Similarity of groups at baseline
Diagnostic assessment

$0 \%$

\section{Pre-to-Post Between-Group Effects}

\section{Main Findings}

Table 1 provides an overview of the pre-to-post between-group effects. For depression (89 comparisons) and anxiety (74 comparisons), significant moderate and small effects were observed (depression: $g=0.34,95 \%$ CI 0.18 to $0.50, P<.001$; anxiety: $g=0.26,95 \%$ CI $0.18-0.33, P<.001)$. Significant, moderate effects were found for stress (56 comparisons; $g=0.44$, 95\% CI 0.32-0.55, $P<.001$ ) and mindfulness (72 comparisons; $g=0.40,95 \%$ CI $0.30-0.50, P<.001)$. No significant effect was observed for well-being ( 52 comparisons; $g=0.21,95 \% \mathrm{CI}-0.03$ to $0.45, P=.08)$. The level of heterogeneity was moderate to

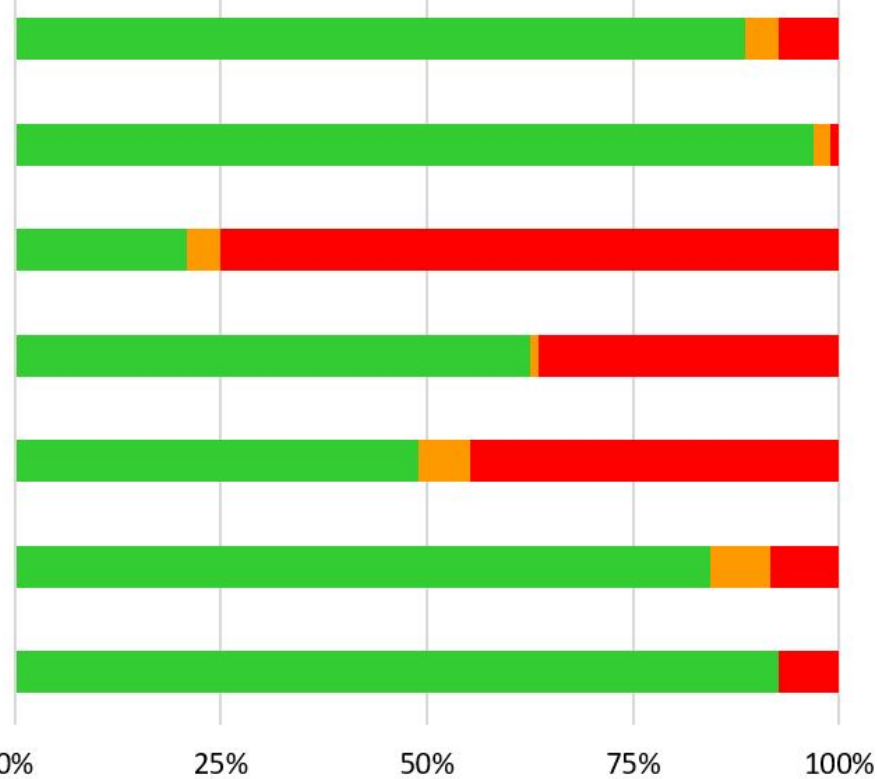

high $\left(I^{2}=64.92-96.64\right)$. When outliers were removed, similar effect sizes were observed (depression: $g=0.30$; anxiety: $g=0.22$; stress: $g=0.38$; well-being: $g=0.22$; and mindfulness: $g=0.39$ ), with no changes in significance of the effect except for well-being $(P<.001)$, and the level of heterogeneity remained moderate to high $\left(I^{2}=41.26-93.23\right)$. After omitting low-quality studies from the analysis, the effect size for well-being was significant $(g=0.26,95 \%$ CI $0.12-0.41 ; P<.001)$. For the remaining outcomes, no significant changes were observed for any of the outcomes, and all effect sizes remained virtually the same. Heterogeneity remained moderate to high $\left(I^{2}=65.72-83.06\right)$. 
Table 1. Pre-to-post effects of online mindfulness-based interventions compared with controls ${ }^{\mathrm{a}}$.

\begin{tabular}{|c|c|c|c|c|c|c|}
\hline \multirow[t]{2}{*}{ Outcomes } & \multirow[t]{2}{*}{$N_{\text {comp }}{ }^{\mathrm{b}}$} & \multirow[t]{2}{*}{ Hedges $g(95 \% \mathrm{CI})$} & \multirow[t]{2}{*}{$Z$} & \multicolumn{2}{|c|}{ Heterogeneity } & \multirow[t]{2}{*}{ Fail-safe $N$} \\
\hline & & & & $Q$ value & $I^{2}$ & \\
\hline \multicolumn{7}{|c|}{ All studies (including outliers) } \\
\hline Depression & 89 & 0.34 (0.18 to 0.50$)$ & $4.10^{\mathrm{c}}$ & $1326.41^{\mathrm{c}}$ & 93.37 & 5507 \\
\hline Anxiety & 74 & $0.26(0.18$ to 0.33$)$ & $6.70^{\mathrm{c}}$ & $208.10^{\mathrm{c}}$ & 64.92 & 2763 \\
\hline Stress & 56 & $0.44(0.32$ to 0.55$)$ & $7.48^{\mathrm{c}}$ & $262.80^{\mathrm{c}}$ & 79.07 & 1355 \\
\hline Well-being & 52 & $0.21(-0.03$ to 0.45$)$ & 1.75 & $1516.62^{\mathrm{c}}$ & 96.64 & 121 \\
\hline Mindfulness & 72 & $0.40(0.30$ to 0.50$)$ & $7.72^{\mathrm{c}}$ & $407.80^{\mathrm{c}}$ & 82.59 & 2624 \\
\hline \multicolumn{7}{|c|}{ All studies (excluding outliers) } \\
\hline Depression $^{\mathrm{d}}$ & 86 & $0.30(0.14$ to 0.46$)$ & $3.69^{\mathrm{c}}$ & $1254.96^{\mathrm{c}}$ & 93.23 & 2903 \\
\hline Anxiety ${ }^{\mathrm{e}}$ & 67 & $0.22(0.15$ to 0.28$)$ & $6.62^{\mathrm{c}}$ & $112.35^{\mathrm{c}}$ & 41.26 & 1217 \\
\hline Stress $^{\mathrm{f}}$ & 47 & $0.38(0.29$ to 0.48$)$ & $7.72^{\mathrm{c}}$ & $130.94^{\mathrm{c}}$ & 64.87 & 1947 \\
\hline Well-being $\mathrm{g}$ & 46 & $0.22(0.15$ to 0.29$)$ & $6.02^{\mathrm{c}}$ & $89.18^{\mathrm{c}}$ & 49.54 & 727 \\
\hline Mindfulness ${ }^{\mathrm{h}}$ & 65 & $0.39(0.29$ to 0.49$)$ & $7.65^{\mathrm{c}}$ & $180.91^{\mathrm{c}}$ & 74.37 & 3719 \\
\hline \multicolumn{7}{|c|}{ Moderate- and high-quality studies } \\
\hline Depression & 61 & $0.37(0.27$ to 0.47$)$ & $7.43^{\mathrm{c}}$ & $237.26^{\mathrm{c}}$ & 74.71 & 2196 \\
\hline Anxiety & 55 & $0.28(0.20$ to 0.37$)$ & $6.35^{\mathrm{c}}$ & $157.54^{\mathrm{c}}$ & 65.72 & 1563 \\
\hline Stress & 38 & $0.39(0.27$ to 0.51$)$ & $6.26^{\mathrm{c}}$ & $159.77^{\mathrm{c}}$ & 76.84 & 1433 \\
\hline Well-being & 31 & $0.26(0.12$ to 0.41$)$ & $3.50^{\mathrm{c}}$ & $154.25^{\mathrm{c}}$ & 80.55 & 398 \\
\hline Mindfulness & 45 & $0.43(0.29$ to 0.56$)$ & $6.20^{\mathrm{c}}$ & $259.72^{\mathrm{c}}$ & 83.06 & 2486 \\
\hline
\end{tabular}

\footnotetext{
${ }^{\mathrm{a}}$ Analyses were conducted using a random effects model.

${ }^{\mathrm{b}} N_{\text {comp }}$ : number of comparisons.

${ }^{\mathrm{c}} P<.001$.

${ }^{\mathrm{d}}$ Three outliers were removed: Kladnitski et al [34] (study 4); Querstret et al [35,36]; Yang et al [37].

${ }^{\text {e}}$ Seven outliers were removed: Forbes et al [38] (study 1); Gao, M (unpublished data, 2021); Levin et al [48]; Mak et al [39]; Querstret et al [35,36]; Segal et al [40]; Yang et al [37].

${ }^{\mathrm{f}}$ Nine outliers were removed: Allexandre et al [41] (study 1); Beshai et al [42]; Champion et al [43]; El Morr et al [44]; Huberty et al [45]; Kladnitski et al [34] (study 4); Levin et al [46]; Nadler et al [128]; Walsh et al [47].

${ }^{\mathrm{g}}$ Six outliers were removed: Allexandre et al [41] (study 1); Hoffmann et al [129]; Levin et al [130] (study 1); Levin et al [48]; Ly et al [49]; Mak et al [39].

${ }^{\mathrm{h}}$ Seven outliers were removed: Forbes et al [38]; Henriksson et al [131]; Huberty et al [45]; Krusche et al [132]; Mak et al [33] (study 1 and study 2); Nadler et al [128].
}

\section{Publication Bias}

Whereas visual inspection of funnel plots indicated no remarkable evidence of publication bias, trim-and-fill analyses and fail-safe numbers suggest that publication bias has occurred in the reporting of effects on depressive and anxiety symptoms, well-being, and mindfulness. The Duval and Tweedie [133] trim-and-fill procedure indicated publication bias for depression, anxiety, and well-being. After adjustment for missing studies $(\mathrm{n}=19)$, the effect size for well-being dropped from $g=0.21$ to $g=-0.04$ (95\% CI -0.23 to 0.15 ). For anxiety and depression, effect sizes were found to be higher, with three imputed studies on anxiety ( $g=0.31,95 \%$ CI $0.23-0.38)$ and 19 on depression ( $g=0.48,95 \%$ CI $0.39-0.57)$.

\section{Subgroup Analyses}

Subgroup analyses can be found in Multimedia Appendix 3. For stress, two subgroup analyses resulted in significantly higher effect sizes: (1) guided online MBIs compared with unguided online MBIs (guided: $g=0.61,95 \%$ CI $0.43-0.82$; unguided: $g=0.34,95 \%$ CI $0.21-0.47 ; P=.02$ ) and (2) studies that used an inactive control condition compared with studies with an active control group (inactive: $g=0.56,95 \%$ CI $0.43-0.69$; active: $g=0.15,95 \%$ CI -0.04 to $0.35 ; P=.001)$. For mindfulness, inactive control groups also resulted in higher effect sizes than 
active control groups (inactive: $g=0.52,95 \%$ CI $0.41-0.63$; active: $g=0.19,95 \%$ CI $0.03-0.34 ; P<.001)$. For anxiety, higher effect sizes were found in samples with psychological symptoms than in those with physical or no symptoms (psychological symptoms: $g=0.47,95 \%$ CI $0.33-0.61$; physical symptoms: $g=0.16$, 95\% CI 0.03-0.30; no symptoms: $g=0.21,95 \%$ CI 0.11-0.030; $P=.008)$. For depression and well-being, no significant differences were found between subgroups.

\section{Meta-Regression Analysis}

The meta-regression analysis (Table 2) revealed that study quality had a significant positive influence on the observed effects of anxiety but not on the remaining outcomes. Furthermore, a significant moderating impact of age on stress was observed, whereby online MBIs were found to be more effective in reducing stress in older samples. For mindfulness, the number of sessions had a significant negative influence on the effect size, with more sessions resulting in lower effect sizes.

Table 2. Meta-regression analyses ${ }^{\mathrm{a}}$.

\begin{tabular}{|c|c|c|c|c|}
\hline Outcome and predictor & $N_{\text {comp }}{ }^{\mathrm{b}}$ & Slope & $Z$ & $P$ value \\
\hline \multicolumn{5}{|l|}{ Depression } \\
\hline Study quality & 88 & 0.05 & 1.09 & .28 \\
\hline$N$ sessions & 84 & 0 & 0 & .99 \\
\hline Mean age & 80 & 0 & 0.47 & .64 \\
\hline$\%$ female & 87 & 0.01 & 1.37 & .18 \\
\hline \multicolumn{5}{|l|}{ Anxiety } \\
\hline Study quality & 73 & 0.07 & 2.04 & $.04^{\mathrm{c}}$ \\
\hline$N$ sessions & 69 & 0 & -1.25 & .21 \\
\hline Mean age & 66 & 0 & -0.03 & .98 \\
\hline$\%$ female & 73 & 0 & 0.83 & .40 \\
\hline \multicolumn{5}{|l|}{ Stress } \\
\hline Study quality & 55 & -0.04 & -0.74 & .46 \\
\hline$N$ sessions & 49 & 0.03 & 2.45 & .05 \\
\hline Mean age & 43 & 0.01 & 2.88 & $.004^{\mathrm{d}}$ \\
\hline$\%$ female & 55 & 0 & 0.25 & .80 \\
\hline \multicolumn{5}{|l|}{ Well-being } \\
\hline Study quality & 51 & 0.07 & 0.90 & .37 \\
\hline$N$ sessions & 49 & 0 & -0.33 & .74 \\
\hline Mean age & 51 & 0 & -0.28 & .78 \\
\hline$\%$ female & 51 & 0 & 0.17 & .86 \\
\hline \multicolumn{5}{|l|}{ Mindfulness } \\
\hline Study quality & 71 & 0.01 & 0.26 & .80 \\
\hline$N$ sessions & 66 & -0.01 & -2.80 & $.005^{\mathrm{d}}$ \\
\hline Mean age & 65 & 0 & 0.06 & .95 \\
\hline$\%$ female & 71 & 0.01 & 1.83 & .07 \\
\hline
\end{tabular}

${ }^{\mathrm{a}}$ Meta-regression analyses were conducted using a mixed effects model with unrestricted maximum likelihood.

${ }^{\mathrm{b}} N_{\text {comp }}$ : number of comparisons.

${ }^{\mathrm{c}} P<.05$.

$\mathrm{d}_{P<.01 \text {. }}$

\section{Pre-to-Follow-up Between-Group Effects}

\section{Main Findings}

The pre-to-follow-up effects are shown in Table 3. At follow-up, significant small effects were found for depression (26 comparisons: $g=0.25,95 \% \mathrm{CI} 0.12-0.38, P<.001)$, and anxiety (21 comparisons: $g=0.23$, 95\% CI $0.13-0.32 ; P<.001$ ). The effects of stress were in favor of control conditions (15 comparisons: $g=-0.24,95 \% \mathrm{CI}-0.40$ to $-0.09, P=.003)$. Effect sizes for well-being ( 18 comparisons: $g=-0.02,95 \% \mathrm{CI}-0.53$ to $0.49, P=.08$ ) and mindfulness (27 comparisons: $g=0.06,95 \%$ 
CI -0.05 to $0.16, P=.28$ ) were not significant. Heterogeneity varied considerably, from $I^{2}=36.49$ for stress to $I^{2}=98.73$ for well-being. After the removal of outliers, effect sizes for depression and mindfulness remained fairly the same (depression: $g=0.27,95 \%$ CI $0.14-0.40, P<.001$; mindfulness: $g=0.05,95 \% \mathrm{CI}-0.03$ to $0.14, P=.21$ ), with no changes in the significance of the effect and the level of heterogeneity remaining moderate $\left(I^{2}=40.36-53.930\right)$. For stress, the effect size was higher after removing outliers (stress: $g=-0.11,95 \%$ CI -0.21 to $-0.02, P=.02)$. The fixed effects models showed similar results. For anxiety and well-being, no outliers were detected. When only medium- and high-quality studies were included, similar effect sizes were found for all outcomes, except for well-being which showed a substantial increase in effect size from $g=-0.02$ to $g=0.17$ (nonsignificant, $95 \% \mathrm{CI}-0.03$ to $-0.37, P=.09$ ). Effect sizes for depression, anxiety, and stress remained significant (depression: $g=0.24$, 95\% CI 0.09-0.38, $P=.001$; anxiety: $g=0.21,95 \%$ CI $0.07-0.34, P=.003$; stress: $g=-0.30,95 \% \mathrm{CI}-0.51$ to $0.08, P=.008)$, with moderate heterogeneity (depression: $I^{2}=53.21$; anxiety: $I^{2}=43.56$; stress: $\left.I^{2}=71.02\right)$. The effect size for mindfulness remained nonsignificant $(g=0.08,95 \% \mathrm{CI}-0.08$ to $0.23 ; P=.34)$, with moderate heterogeneity $\left(I^{2}=70.06\right)$.

Table 3. Pre-to-follow-up effects of online mindfulness-based interventions compared with controls ${ }^{\mathrm{a}}$.

\begin{tabular}{lllll}
\hline Outcomes & $N_{\text {comp }}$ b & Hedges $g(95 \% \mathrm{CI}))$ & $Z$ & Heterogeneity \\
& & $Q$ value & $I^{2}$ \\
\hline
\end{tabular}

\begin{tabular}{|c|c|c|c|c|c|c|}
\hline \multicolumn{7}{|c|}{ All studies (including outliers) } \\
\hline Depression & 26 & 0.25 (0.12 to 0.38$)$ & $3.80^{\mathrm{c}}$ & $74.12^{\mathrm{c}}$ & 66.27 & 201 \\
\hline Anxiety & 21 & 0.23 (0.13 to 0.32$)$ & $4.62^{\mathrm{c}}$ & $31.49^{\mathrm{d}}$ & 36.49 & 189 \\
\hline Stress & 15 & $-0.24(-0.40$ to -0.08$)$ & $-2.97^{\mathrm{e}}$ & $37.09^{\mathrm{e}}$ & 62.25 & 71 \\
\hline Well-being & 18 & $-0.02(-0.53$ to 0.49$)$ & -0.09 & $1254.86^{\mathrm{c}}$ & 98.73 & 171 \\
\hline Mindfulness & 27 & $0.06(-0.05$ to 0.16$)$ & 1.09 & $75.05^{\mathrm{c}}$ & 65.36 & 0 \\
\hline \multicolumn{7}{|c|}{ All studies (excluding outliers) } \\
\hline Depression $^{\mathrm{f}}$ & 25 & $0.27(0.14$ to 0.40$)$ & $4.18^{\mathrm{c}}$ & $53.93^{\mathrm{c}}$ & 55.50 & 220 \\
\hline Anxiety & $\mathrm{N} / \mathrm{A}^{\mathrm{g}}$ & N/A & N/A & N/A & N/A & N/A \\
\hline Stress $^{\mathrm{h}}$ & 13 & $-0.11(-0.21$ to -0.02$)$ & $-2.31^{\mathrm{d}}$ & 9.35 & 0 & 12 \\
\hline Well-being & N/A & N/A & N/A & N/A & N/A & N/A \\
\hline Mindfulness ${ }^{\mathrm{i}}$ & 25 & $0.05(-0.03$ to 0.14$)$ & 1.23 & $40.36^{\mathrm{d}}$ & 40.53 & 0 \\
\hline \multicolumn{7}{|c|}{ Medium- and high-quality studies } \\
\hline Depression & 16 & $0.24(0.09$ to 0.38$)$ & $3.23^{\mathrm{e}}$ & $32.06^{\mathrm{e}}$ & 53.21 & 75 \\
\hline Anxiety & 13 & $0.21(0.07$ to 0.34$)$ & $2.99^{\mathrm{e}}$ & $21.26^{\mathrm{d}}$ & 43.56 & 45 \\
\hline Stress & 11 & $-0.30(-0.51$ to -0.08$)$ & $-2.67^{\mathrm{e}}$ & $34.51^{\mathrm{c}}$ & 71.02 & 44 \\
\hline Well-being & 13 & $0.17(-0.03$ to 0.37$)$ & 1.71 & $48.02^{\mathrm{c}}$ & 75.00 & 24 \\
\hline Mindfulness & 18 & $0.08(-0.08$ to 0.23$)$ & 0.96 & $56.78^{\mathrm{c}}$ & 70.06 & 0 \\
\hline
\end{tabular}

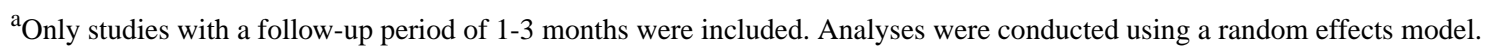

${ }^{\mathrm{b}} N_{\text {comp }}$ : number of comparisons.

${ }^{\mathrm{c}} P<.001$.

${ }^{\mathrm{d}} P<.05$.

${ }^{\mathrm{e}} P<.01$.

${ }^{\mathrm{f}}$ One outlier was removed: Mak et al [39].

$\mathrm{g}_{\mathrm{N} / \mathrm{A} \text { : not applicable. }}$

${ }^{\mathrm{h}}$ Two outliers were removed: Kladnitski et al [34] (studies 1 and 3).

${ }^{\mathrm{i}}$ Two outliers were removed: Pots et al [50] and Huberty et al [45].
} 


\section{Publication Bias}

For depression, anxiety, and well-being, funnel plots were somewhat skewed in favor of studies with a positive outcome at follow-up. The trim-and-fill procedure by Duval and Tweedie indicated publication bias for all outcomes except stress; 1, 3, 6 , and 6 studies were trimmed for depression, anxiety, well-being, and mindfulness, respectively. The adjusted effect sizes for depression $(g=0.26,95 \%$ CI $0.13-0.39)$, anxiety $(g=0.18,95 \%$ CI $0.07-0.29)$, and stress ( $g=-0.24,95 \%$ CI -0.40 to -0.08$)$ were similar to the unadjusted effect sizes, whereas effect sizes for mindfulness ( $g=-0.04,95 \%$ CI -0.14 to 0.07 ) and well-being ( $g=-038,95 \% \mathrm{CI}-0.81$ to 0.06 ) showed a considerable decline after adjusting for missing studies. Finally, the fail-safe $N$ indicated that findings for depression, anxiety, and well-being may be considered robust, whereas this was not the case for stress and mindfulness. However, when only moderate-to-high quality studies were included in the analysis, for none of the remaining outcomes, the findings were deemed robust based on the fail-safe $N$.

\section{Discussion}

\section{Principal Findings}

An updated meta-analysis was conducted to assess the effects of the booming field of online MBIs on mental health across studies. In total, 97 RCTs were included in this meta-analysis, demonstrating the rapidly growing interest in implementing MBIs via eHealth platforms and apps. In comparison, only 15 RCTs were included in our meta-analysis conducted 5 years ago [28]. Overall, significant moderate pre-to-post effects were observed for depression $(g=0.34)$, stress $(g=0.44)$, and mindfulness $(g=0.40)$, and a significant small effect was found for anxiety $(g=0.26)$. After removing outliers and low-quality studies, similar results were found, except for well-being. Pre-to-follow-up analyses demonstrated significant small effects for depression and anxiety ( $g=0.25$ and $g=0.23$, respectively). Our findings are largely in line with those reported in previous meta-analyses [9,10,28-30] and suggest that online MBIs have a significant low-to-moderate impact on mental health and that these effects are maintained at short-term follow-up.

Thus, when addressing depression and anxiety, the impact of online MBIs appears similar to MBIs in traditional face-to-face format [14,23], as well as to other common interventions such as cognitive behavioral therapy [134,135]. However, offering these interventions in an online format may have unique benefits of increased accessibility and scalability, thereby lowering the threshold for participation [136] and potential cost-effectiveness [137]. In addition, in the case of an app-based mode of delivery, the presence of a mobile device throughout most daily activities and experiences may facilitate the integration of newly learned skills into daily life $[138,139]$. Indeed, just-in-time information (eg, reminders) has been shown to contribute to the effectiveness of online MBIs [140]. Future research could further investigate the level of integration of skills learned in MBIs into daily life by using methods that allow for the assessment of daily fluctuations and situational contexts (eg, experience sampling methods) [141].
Our findings on well-being deserve special attention. In our updated meta-analysis, a significantly small effect on well-being was found, but only after omitting outliers $(g=0.22)$ and low-quality studies $(g=0.26)$. This is in contrast with our previous meta-analysis [28], where there was no difference in the effect on well-being when including or excluding low-quality trials. At first glance, one may consider the increase in the proportion of low-quality trials among those trials assessing well-being, from $13 \%$ (1/8 studies) to $36 \%$ (14/39 studies), as a possible explanation. As a result, studies of low quality may exert a larger influence on the effect size for well-being. However, this line of thought seems contradictory to our finding that study quality is not a moderator of the effect of online MBIs on well-being. Another potential explanation for this finding is that we used a different method to calculate the effect sizes for well-being. In our previous meta-analysis, we used the most valid outcome measure to compute the effect size. However, following the conceptualization of well-being by Keyes [142], in this meta-analysis, we computed combined effect sizes incorporating emotional, psychological, and social dimensions of well-being, where possible. Although we feel that this is the preferred method, this might have led to somewhat different results. In addition, we recognize a growing variability across studies as to how well-being is conceptualized and measured, which might have impacted the results. This is reflected in the increased levels of heterogeneity compared with our previous meta-analysis. Although heterogeneity was low to moderate $\left(I^{2}=32.86\right.$, when including all studies $)$ in our meta-analysis published in 2016 [28], we found a heterogeneity level approaching $100 \%\left(I^{2}=96.64\right)$ in this study. This calls for a more consistent assessment of well-being in future trials assessing the effectiveness of online MBIs. We support the recommendation by Chakhssi et al [143] that studies investigating the effects of interventions, in this case online MBIs, on well-being ideally include validated measures for emotional, psychological, and social dimensions of well-being.

The finding that studies of moderate-to-high quality indicate a positive impact of online MBIs on well-being is important because interventions such as MBSR, MBCT, and ACT emphasize well-being as an intervention outcome. Its relevance is further underlined by increasing evidence that mental well-being and mental illness are related yet discernible phenomena [144-146] and that higher levels of mental well-being reduce the incidence of mental health problems [147-149].

Remarkably, where online MBSR and online MBCT were the most prominent online MBIs 5 years ago, in this meta-analysis, online ACT dominates the field; 29 studies evaluated the impact of online ACT interventions compared with 5 studies in 2016 [28]. ACT is a distinct model of behavioral therapy, emphasizing the context and function of psychological phenomena as the target of psychological treatment [7]. Moderate-to-large effects on mental health have been found across studies evaluating the impact of ACT in clinical and nonclinical populations [21,150]. This meta-analysis thus shows that ACT is increasingly implemented as an online intervention in comparison with other types of MBIs. We found significant small effects of online ACT on depression $(g=0.35)$, anxiety $(g=0.23)$, and well-being 
( $g=0.21)$, which is consistent with the findings of two other meta-analyses on the effectiveness of web-delivered ACT [151,152].

Whereas online ACT may have become an increasingly common type of intervention in this field of study, another development that is mirrored by our findings is that interventions are increasingly nonspecific. In $42.5 \%$ (53/125) of the comparisons, mixed or hybrid interventions, encompassing elements of both MBSR and MBCT as well as other mindfulness-based exercises, were used. We found that these programs prove to be effective in reducing symptoms of depression $(g=0.37)$, anxiety $(g=0.30)$, and stress $(g=0.44)$, as well as in improving well-being $(g=0.30)$ and mindfulness $(g=0.40)$, an important finding considering that hybrid interventions are increasingly conquering the market of online MBIs. Interestingly, the type of intervention was not found to be a significant moderator of the effectiveness of online MBIs, suggesting that MBSR, MBCT, ACT, and hybrid MBIs are equally effective in improving mental health.

Subgroup analyses yielded significant differential effects of guidance, symptoms, and type of control group on stress, anxiety, and mindfulness. The effects of online MBIs on stress were significantly higher for interventions with therapist guidance $(g=0.42)$ than for interventions without guidance $(g=0.21)$. This is in line with our previous meta-analysis [28] and evidence demonstrating that guided interventions are more effective in reducing distress than unguided interventions [153]. Furthermore, the effects on anxiety were higher for samples with psychological symptoms than for those with physical or no symptoms. Populations without psychological symptoms may have less room to improve their psychological symptoms, due to lower baseline scores for anxiety (ie, a floor effect). In addition, the effects on stress and mindfulness were significantly larger when comparing online MBIs with inactive versus active control groups. In this regard, it should be noted that levels of heterogeneity were substantial, that is, it is questionable that indeed the types of subgroups are responsible for the differential outcomes. However, these results are in line with the common finding that effect sizes are related to the type of control group [154], with waiting list control groups typically yielding the largest effects [155].

Although the field of online mindfulness is booming, we noticed a number of undesirable phenomena that may undermine the accumulation of unbiased scientific knowledge in this specific domain, thereby hampering the development and optimization of novel online MBIs. The first phenomenon was related to adherence. Adherence is an important topic in the context of online interventions [156] and can be defined as the proportion of an intervention a person engages with or completes [157]. In this meta-analysis, it was found that although $70 \%(68 / 97)$ of studies reported relevant information regarding adherence to the intervention (eg, time spent on the intervention and number of modules started), only in $23 \%$ (22/97) of studies a definition or cut-off was provided for determining adherence versus nonadherence. This corroborates with an important systematic review demonstrating that a minority of studies evaluating eHealth interventions described a threshold for the intended use of the technology and that only $10 \%$ of the included studies reported a justification of the intended use [158]. The clinical relevance of online interventions is clear, as poor adherence may limit the effects of an intervention as a suboptimal dosage of the treatment may be received. For online MBIs, the relevance may be even bigger as regular practice of mindfulness is assumed to be essential for the development of mindfulness skills [159]. Therefore, describing a justified threshold for intended use that is aligned with the aim of the technology seems not only relevant but also important for future studies, as this is the basis for a more precise evaluation of adherence and the impact of an intervention.

The indications for publication bias that were found for all outcomes except stress represent a second phenomenon. The pre-post effect size for well-being was substantially reduced after adjusting for missing studies, whereas pre-post findings for depression and anxiety indicated the opposite. We encourage researchers and publishers to publish not only studies with positive outcomes but also studies with nonsignificant or negative findings to overcome the accumulation of unbiased scientific knowledge and the unduly hampering optimization of novel online MBIs.

A third phenomenon that should be addressed is an increase in the proportion of studies with a high risk of bias from $20 \%(3 / 15$ studies) in our previous meta-analysis [28] to $34 \%(33 / 97$ studies) in this meta-analysis. In addition, in our meta-analysis, low trial quality resulted in biased effect sizes for well-being. This is an undesirable trend that potentially undermines the reliability of research in this specific domain. Most studies did not meet two of the seven criteria used for rating the quality of studies. Nearly $78 \%$ (76/97) of the studies did not perform an adequate drop-out analysis, and 51\% (49/97) of the studies did not conduct adequate power analysis. Therefore, attention to these specific analyses in future studies is highly recommended.

\section{Limitations}

This meta-analysis included a large number of studies, which allowed moderator analyses and long-term follow-up measurements. However, some important limitations of this study must be considered. There was great variability in follow-up measurements, and the studies included in this meta-analysis only allowed for an overall assessment of effects until the 3-month follow-up. Owing to the limited number of studies using longer follow-up times (longer than 3 months), it remains unclear whether the effects of online MBIs remain at long-term follow-up. It should also be noted that heterogeneity was high for most moderator analyses. This suggests that other, yet unknown, factors may explain the effect differences rather than the observed factors.

\section{Conclusions}

This updated meta-analysis not only demonstrates that the field of online MBIs is booming, with a significant low-to-moderate impact on mental health, but also corroborates previous evidence that online MBIs are beneficial for a wide range of populations and symptoms. Future trials assessing the effectiveness of online MBIs should focus on methodological quality parameters, on a priori definition and monitoring of adherence, and on longer follow-up measurements. 


\section{Authors' Contributions}

MSS and WP designed the study. MSS and JA conducted the literature search. MSS, JA, and WP performed data extraction and analyses. EB was an advisor for the project. MSS prepared the first draft of the manuscript, and all authors contributed to and approved the final manuscript.

\section{Conflicts of Interest}

None declared.

\section{Multimedia Appendix 1}

Study characteristics and outcome measures.

[DOCX File, 82 KB-Multimedia Appendix 1]

\section{Multimedia Appendix 2}

Methodological quality of studies included in the meta-analysis.

[DOCX File, 34 KB-Multimedia Appendix 2]

\section{Multimedia Appendix 3}

Subgroup analyses.

[DOCX File, 37 KB-Multimedia Appendix 3]

\section{References}

1. Keng S, Smoski MJ, Robins CJ. Effects of mindfulness on psychological health: a review of empirical studies. Clin Psychol Rev 2011 Aug;31(6):1041-1056 [FREE Full text] [doi: 10.1016/j.cpr.2011.04.006] [Medline: 21802619]

2. Kabat-Zinn J. Full Catastrophe Living: Using the Wisdom of Your Body and Mind to Face Stress, Pain and Illness. New York: Delacorte; 1990:1-720.

3. Weed LL. Medical records that guide and teach. N Engl J Med 1968 Mar 21;278(12):652-657. [doi: 10.1056/NEJM196803212781204] [Medline: 5637250]

4. Kabat-Zinn J. An outpatient program in behavioral medicine for chronic pain patients based on the practice of mindfulness meditation: theoretical considerations and preliminary results. Gen Hosp Psychiatry 1982 Apr;4(1):33-47. [doi: 10.1016/0163-8343(82)90026-3] [Medline: 7042457]

5. Segal Z, Williams J, Teasdale J. Mindfulness-Based Cognitive Therapy for Depression: A New Approach to Preventing Relapse. New York: The Guilford Press; 2002:1-351.

6. Linehan M. Cognitive-Bhavioral Treatment of Borderline Personality Disorder. New York: Guilford Press; 1993:1-558.

7. Hayes S, Strosahl K, Wilson K. Acceptance and Commitment Therapy: An Experiential Approach to Behavior Change. New York: Guilford Press; 1999:1-304.

8. Zainal NZ, Booth S, Huppert FA. The efficacy of mindfulness-based stress reduction on mental health of breast cancer patients: a meta-analysis. Psychooncology 2013 Jul;22(7):1457-1465. [doi: 10.1002/pon.3171] [Medline: 22961994]

9. Sevilla-Llewellyn-Jones J, Santesteban-Echarri O, Pryor I, McGorry P, Alvarez-Jimenez M. Web-based mindfulness interventions for mental health treatment: systematic review and meta-analysis. JMIR Ment Health 2018 Sep 25;5(3):e10278 [FREE Full text] [doi: 10.2196/10278] [Medline: 30274963]

10. O'Connor M, Munnelly A, Whelan R, McHugh L. The efficacy and acceptability of third-wave behavioral and cognitive ehealth treatments: a systematic review and meta-analysis of randomized controlled trials. Behav Ther 2018 May;49(3):459-475. [doi: 10.1016/j.beth.2017.07.007] [Medline: 29704973]

11. Zoogman S, Goldberg SB, Hoyt WT, Miller L. Mindfulness interventions with youth: a meta-analysis. Mindfulness 2014 Jan 15;6(2):290-302. [doi: 10.1007/s12671-013-0260-4]

12. Gu J, Strauss C, Bond R, Cavanagh K. How do mindfulness-based cognitive therapy and mindfulness-based stress reduction improve mental health and wellbeing? A systematic review and meta-analysis of mediation studies. Clin Psychol Rev 2015 Apr;37:1-12. [doi: 10.1016/j.cpr.2015.01.006] [Medline: 25689576]

13. Hilton L, Hempel S, Ewing BA, Apaydin E, Xenakis L, Newberry S, et al. Mindfulness meditation for chronic pain: systematic review and meta-analysis. Ann Behav Med 2017 Apr;51(2):199-213 [FREE Full text] [doi:

10.1007/s12160-016-9844-2] [Medline: 27658913]

14. Goldberg SB, Tucker RP, Greene PA, Davidson RJ, Wampold BE, Kearney DJ, et al. Mindfulness-based interventions for psychiatric disorders: a systematic review and meta-analysis. Clin Psychol Rev 2018 Feb;59:52-60 [FREE Full text] [doi: 10.1016/j.cpr.2017.10.011] [Medline: 29126747] 
15. Kuyken W, Warren FC, Taylor RS, Whalley B, Crane C, Bondolfi G, et al. Efficacy of mindfulness-based cognitive therapy in prevention of depressive relapse: an individual patient data meta-analysis from randomized trials. JAMA Psychiatry 2016 Jun 01;73(6):565-574. [doi: 10.1001/jamapsychiatry.2016.0076] [Medline: 27119968]

16. Virgili M. Mindfulness-based interventions reduce psychological distress in working adults: a meta-analysis of intervention studies. Mindfulness 2013 Dec 13;6(2):326-337. [doi: 10.1007/s12671-013-0264-0]

17. Godfrey KM, Gallo LC, Afari N. Mindfulness-based interventions for binge eating: a systematic review and meta-analysis. J Behav Med 2015 Apr;38(2):348-362. [doi: 10.1007/s10865-014-9610-5] [Medline: 25417199]

18. Li W, Howard MO, Garland EL, McGovern P, Lazar M. Mindfulness treatment for substance misuse: a systematic review and meta-analysis. J Subst Abuse Treat 2017 Apr;75:62-96. [doi: 10.1016/j.jsat.2017.01.008] [Medline: 28153483]

19. Zhang M, Wen Y, Liu W, Peng L, Wu X, Liu Q. Effectiveness of mindfulness-based therapy for reducing anxiety and depression in patients with cancer: a meta-analysis. Medicine (Baltimore) 2015 Nov;94(45):e0897 [FREE Full text] [doi: 10.1097/MD.0000000000000897] [Medline: 26559246]

20. McCarney RW, Schulz J, Grey AR. Effectiveness of mindfulness-based therapies in reducing symptoms of depression: a meta-analysis. Eur J Psychother Couns 2012 Sep;14(3):279-299. [doi: 10.1080/13642537.2012.713186]

21. Veehof MM, Trompetter HR, Bohlmeijer ET, Schreurs KM. Acceptance- and mindfulness-based interventions for the treatment of chronic pain: a meta-analytic review. Cogn Behav Ther 2016;45(1):5-31. [doi: 10.1080/16506073.2015.1098724] [Medline: 26818413]

22. Stenhoff A, Steadman L, Nevitt S, Benson L, White R. Acceptance and commitment therapy and subjective wellbeing: a systematic review and meta-analyses of randomised controlled trials in adults. J Contextual Behav Sci 2020 Oct;18:256-272 [FREE Full text] [doi: 10.1016/i.jcbs.2020.08.008]

23. Gloster A, Walder N, Levin M, Twohig M, Karekla M. The empirical status of acceptance and commitment therapy: a review of meta-analyses. J Contextual Behav Sci 2020 Oct;18:181-192 [FREE Full text] [doi: 10.1016/j.jcbs.2020.09.009]

24. Querstret D, Morison L, Dickinson S, Cropley M, John M. Mindfulness-based stress reduction and mindfulness-based cognitive therapy for psychological health and well-being in nonclinical samples: a systematic review and meta-analysis. Int J Stress Manag 2020 Nov;27(4):394-411. [doi: 10.1037/str0000165]

25. Riper H, Andersson G, Christensen H, Cuijpers P, Lange A, Eysenbach G. Theme issue on e-mental health: a growing field in internet research. J Med Internet Res 2010 Dec;12(5):e74 [FREE Full text] [doi: 10.2196/jmir.1713] [Medline: 21169177]

26. Barak A, Hen L, Boniel-Nissim M, Shapira N. A comprehensive review and a meta-analysis of the effectiveness of internet-based psychotherapeutic interventions. J Technol Hum 2008 Jul 03;26(2-4):109-160. [doi: 10.1080/15228830802094429]

27. Carlbring P, Andersson G, Cuijpers P, Riper H, Hedman-Lagerlöf E. Internet-based vs. face-to-face cognitive behavior therapy for psychiatric and somatic disorders: an updated systematic review and meta-analysis. Cogn Behav Ther 2018 Jan;47(1):1-18. [doi: 10.1080/16506073.2017.1401115] [Medline: 29215315]

28. Spijkerman MPJ, Pots WTM, Bohlmeijer ET. Effectiveness of online mindfulness-based interventions in improving mental health: a review and meta-analysis of randomised controlled trials. Clin Psychol Rev 2016 Apr;45:102-114 [FREE Full text] [doi: 10.1016/j.cpr.2016.03.009] [Medline: 27111302]

29. Zhang Y, Xue J, Huang Y. A meta-analysis: internet mindfulness-based interventions for stress management in the general population. Medicine (Baltimore) 2020 Jul 10;99(28):e20493. [doi: 10.1097/MD.0000000000020493] [Medline: 32664060]

30. Victorson DE, Sauer CM, Wolters L, Maletich C, Lukoff K, Sufrin N. Meta-analysis of technology-enabled mindfulness-based programs for negative affect and mindful awareness. Mindfulness 2020 Apr 27;11(8):1884-1899. [doi:

10.1007/s12671-020-01373-y]

31. Moher D, Liberati A, Tetzlaff J, Altman DG, PRISMA Group. Preferred reporting items for systematic reviews and meta-analyses: the PRISMA statement. PLoS Med 2009 Jul 21;6(7):e1000097 [FREE Full text] [doi: 10.1371/journal.pmed.1000097] [Medline: 19621072]

32. Wahbeh H, Goodrich E, Oken B. Internet-based mindfulness meditation for cognition and mood in older adults: a pilot study. Altern Ther Health Med 2016;22(2):44-53 [FREE Full text] [Medline: 27036056]

33. Mak WW, Tong AC, Yip SY, Lui WW, Chio FH, Chan AT, et al. Efficacy and moderation of mobile app-based programs for mindfulness-based training, self-compassion training, and cognitive behavioral psychoeducation on mental health: randomized controlled noninferiority trial. JMIR Ment Health 2018 Oct 11;5(4):e60 [FREE Full text] [doi: 10.2196/mental.8597] [Medline: $\underline{30309837]}$

34. Kladnitski N, Smith J, Uppal S, James MA, Allen AR, Andrews G, et al. Transdiagnostic internet-delivered CBT and mindfulness-based treatment for depression and anxiety: a randomised controlled trial. Internet Interv 2020 Apr;20:100310 [FREE Full text] [doi: 10.1016/j.invent.2020.100310] [Medline: 32140427]

35. Querstret D, Cropley M, Fife-Schaw C. Internet-based instructor-led mindfulness for work-related rumination, fatigue, and sleep: Assessing facets of mindfulness as mechanisms of change. A randomized waitlist control trial. J Occup Health Psychol 2017 Apr;22(2):153-169. [doi: 10.1037/ocp0000028] [Medline: 27054503]

36. Querstret D, Cropley M, Fife-Schaw C. The effects of an online mindfulness intervention on perceived stress, depression and anxiety in a non-clinical sample: a randomised waitlist control trial. Mindfulness (N Y) 2018;9(6):1825-1836 [FREE Full text] [doi: 10.1007/s12671-018-0925-0] [Medline: 30524514] 
37. Yang M, Jia G, Sun S, Ye C, Zhang R, Yu X. Effects of an online mindfulness intervention focusing on attention monitoring and acceptance in pregnant women: a randomized controlled trial. J Midwifery Womens Health 2019 Jan;64(1):68-77. [doi: 10.1111/jmwh.12944] [Medline: 30695166]

38. Forbes G, Newton S, Calvete C, Birch J, Dodds J, Steed L, et al. MEMPHIS: a smartphone app using psychological approaches for women with chronic pelvic pain presenting to gynaecology clinics: a randomised feasibility trial. BMJ Open 2020 Mar 12;10(3):e030164 [FREE Full text] [doi: 10.1136/bmjopen-2019-030164] [Medline: 32165549]

39. Mak WW, Chio FH, Chan AT, Lui WW, Wu EK. The efficacy of internet-based mindfulness training and cognitive-behavioral training with telephone support in the enhancement of mental health among college students and young working adults: randomized controlled trial. J Med Internet Res 2017 Mar 22;19(3):e84 [FREE Full text] [doi: 10.2196/jmir.6737] [Medline: 28330831]

40. Segal ZV, Dimidjian S, Beck A, Boggs JM, Vanderkruik R, Metcalf CA, et al. Outcomes of online mindfulness-based cognitive therapy for patients with residual depressive symptoms: a randomized clinical trial. JAMA Psychiatry 2020 Jun 01;77(6):563-573 [FREE Full text] [doi: 10.1001/jamapsychiatry.2019.4693] [Medline: 31995132]

41. Allexandre D, Bernstein AM, Walker E, Hunter J, Roizen MF, Morledge TJ. A web-based mindfulness stress management program in a corporate call center: a randomized clinical trial to evaluate the added benefit of onsite group support. J Occup Environ Med 2016 Mar;58(3):254-264 [FREE Full text] [doi: 10.1097/JOM.0000000000000680] [Medline: 26949875]

42. Beshai S, Bueno C, Yu M, Feeney JR, Pitariu A. Examining the effectiveness of an online program to cultivate mindfulness and self-compassion skills (Mind-OP): randomized controlled trial on Amazon's Mechanical Turk. Behav Res Ther 2020 Nov;134:103724. [doi: 10.1016/j.brat.2020.103724] [Medline: 32942203]

43. Champion L, Economides M, Chandler C. The efficacy of a brief app-based mindfulness intervention on psychosocial outcomes in healthy adults: a pilot randomised controlled trial. PLoS One 2018;13(12):e0209482 [FREE Full text] [doi: 10.1371/journal.pone.0209482] [Medline: 30596696]

44. Morr C, Ritvo P, Ahmad F, Moineddin R, Team M. Effectiveness of an 8-week web-based mindfulness virtual community intervention for university students on symptoms of stress, anxiety, and depression: randomized controlled trial. JMIR Ment Health 2020 Jul 17;7(7):e18595 [FREE Full text] [doi: 10.2196/18595] [Medline: 32554380]

45. Huberty J, Green J, Glissmann C, Larkey L, Puzia M, Lee C. Efficacy of the mindfulness meditation mobile app "Calm" to reduce stress among college students: randomized controlled trial. JMIR Mhealth Uhealth 2019 Jun 25;7(6):e14273 [FREE Full text] [doi: 10.2196/14273] [Medline: 31237569]

46. Levin ME, Hayes SC, Pistorello J, Seeley JR. Web-based self-help for preventing mental health problems in universities: comparing acceptance and commitment training to mental health education. J Clin Psychol 2016 Mar;72(3):207-225. [doi: 10.1002/jclp.22254] [Medline: 26784010]

47. Walsh KM, Saab BJ, Farb NA. Effects of a mindfulness meditation app on subjective well-being: active randomized controlled trial and experience sampling study. JMIR Ment Health 2019 Jan 08;6(1):e10844 [FREE Full text] [doi: 10.2196/10844] [Medline: 30622094]

48. Levin ME, Krafft J, Hicks ET, Pierce B, Twohig MP. A randomized dismantling trial of the open and engaged components of acceptance and commitment therapy in an online intervention for distressed college students. Behav Res Ther 2020 Mar;126:103557. [doi: 10.1016/j.brat.2020.103557] [Medline: 32014692]

49. Ly KH, Trüschel A, Jarl L, Magnusson S, Windahl T, Johansson R, et al. Behavioural activation versus mindfulness-based guided self-help treatment administered through a smartphone application: a randomised controlled trial. BMJ Open 2014 Jan 09;4(1):e003440 [FREE Full text] [doi: 10.1136/bmjopen-2013-003440] [Medline: 24413342]

50. Pots WT, Fledderus M, Meulenbeek PA, ten Klooster PM, Schreurs KM, Bohlmeijer ET. Acceptance and commitment therapy as a web-based intervention for depressive symptoms: randomised controlled trial. Br J Psychiatry 2016 Jan;208(1):69-77. [doi: 10.1192/bjp.bp.114.146068] [Medline: 26250745]

51. Ahmad F, El Morr C, Ritvo P, Othman N, Moineddin R, Team M. An eight-week, web-based mindfulness virtual community intervention for students' mental health: randomized controlled trial. JMIR Ment Health 2020 Feb 18;7(2):e15520 [FREE Full text] [doi: 10.2196/15520] [Medline: 32074061]

52. Aikens KA, Astin J, Pelletier KR, Levanovich K, Baase CM, Park YY, et al. Mindfulness goes to work: impact of an online workplace intervention. J Occup Environ Med 2014 Jul;56(7):721-731. [doi: 10.1097/JOM.0000000000000209] [Medline: 24988100]

53. Barrett K, Stewart I. A preliminary comparison of the efficacy of online Acceptance and Commitment Therapy (ACT) and Cognitive Behavioural Therapy (CBT) stress management interventions for social and healthcare workers. Health Soc Care Community 2021 Jan 01;29(1):113-126. [doi: 10.1111/hsc.13074] [Medline: 32613644]

54. Boettcher J, Aström V, Påhlsson D, Schenström O, Andersson G, Carlbring P. Internet-based mindfulness treatment for anxiety disorders: a randomized controlled trial. Behav Ther 2014 Mar;45(2):241-253 [FREE Full text] [doi: 10.1016/j.beth.2013.11.003] [Medline: 24491199]

55. Bostock S, Crosswell AD, Prather AA, Steptoe A. Mindfulness on-the-go: effects of a mindfulness meditation app on work stress and well-being. J Occup Health Psychol 2019 Feb;24(1):127-138 [FREE Full text] [doi: 10.1037/ocp0000118] [Medline: 29723001] 
56. Bruggeman-Everts FZ, Wolvers MD, van de Schoot R, Vollenbroek-Hutten MM, Van der Lee ML. Effectiveness of two web-based interventions for chronic cancer-related fatigue compared to an active control condition: results of the "Fitter Na Kanker" randomized controlled trial. J Med Internet Res 2017 Oct 19;19(10):e336 [FREE Full text] [doi: 10.2196/jmir.7180] [Medline: 29051138]

57. Buhrman M, Skoglund A, Husell J, Bergström K, Gordh T, Hursti T, et al. Guided internet-delivered acceptance and commitment therapy for chronic pain patients: a randomized controlled trial. Behav Res Ther 2013 Jun;51(6):307-315. [doi: 10.1016/j.brat.2013.02.010] [Medline: 23548250]

58. Cavalera C, Rovaris M, Mendozzi L, Pugnetti L, Garegnani M, Castelnuovo G, et al. Online meditation training for people with multiple sclerosis: a randomized controlled trial. Mult Scler 2019 Apr;25(4):610-617. [doi: 10.1177/1352458518761187] [Medline: 29485319]

59. Cavanagh K, Strauss C, Cicconi F, Griffiths N, Wyper A, Jones F. A randomised controlled trial of a brief online mindfulness-based intervention. Behav Res Ther 2013 Sep;51(9):573-578. [doi: 10.1016/j.brat.2013.06.003] [Medline: 23872699]

60. Cavanagh K, Churchard A, O'Hanlon P, Mundy T, Votolato P, Jones F, et al. A randomised controlled trial of a brief online mindfulness-based intervention in a non-clinical population: replication and extension. Mindfulness (N Y) 2018;9(4):1191-1205 [FREE Full text] [doi: 10.1007/s12671-017-0856-1] [Medline: 30100934]

61. Chapoutot M, Peter-Derex L, Schoendorff B, Faivre T, Bastuji H, Putois B. Telehealth-delivered CBT-I programme enhanced by acceptance and commitment therapy for insomnia and hypnotic dependence: a pilot randomized controlled trial. J Sleep Res 2021 Feb;30(1):e13199. [doi: 10.1111/jsr.13199] [Medline: 33020985]

62. Compen F, Bisseling E, Schellekens M, Donders R, Carlson L, van der Lee M, et al. Face-to-face and internet-based mindfulness-based cognitive therapy compared with treatment as usual in reducing psychological distress in patients with cancer: a multicenter randomized controlled trial. J Clin Oncol 2018 Aug 10;36(23):2413-2421. [doi: 10.1200/JCO.2017.76.5669] [Medline: 29953304]

63. Cox CE, Hough CL, Jones DM, Ungar A, Reagan W, Key MD, et al. Effects of mindfulness training programmes delivered by a self-directed mobile app and by telephone compared with an education programme for survivors of critical illness: a pilot randomised clinical trial. Thorax 2019 Jan;74(1):33-42 [FREE Full text] [doi: 10.1136/thoraxjnl-2017-211264] [Medline: 29793970]

64. De Wit J, Beelen AK, Drossaert CH, Kolijn R, Van Den Berg LH, SchrÖder CD, et al. Blended psychosocial support for partners of patients with ALS and PMA: results of a randomized controlled trial. Amyotroph Lateral Scler Frontotemporal Degener 2020 Aug;21(5-6):344-354. [doi: 10.1080/21678421.2020.1757114] [Medline: $\underline{32362155]}$

65. Dowd H, Hogan MJ, McGuire BE, Davis MC, Sarma KM, Fish RA, et al. Comparison of an online mindfulness-based cognitive therapy intervention with online pain management psychoeducation: a randomized controlled study. Clin J Pain 2015 Jun;31(6):517-527. [doi: 10.1097/AJP.0000000000000201] [Medline: 25565584]

66. Eriksson T, Germundsjö L, Åström E, Rönnlund M. Mindful self-compassion training reduces stress and burnout symptoms among practicing psychologists: a randomized controlled trial of a brief web-based intervention. Front Psychol 2018;9:2340 [FREE Full text] [doi: 10.3389/fpsyg.2018.02340] [Medline: $\underline{\text { 30538656] }}$

67. Eustis EH, Hayes-Skelton SA, Orsillo SM, Roemer L. Surviving and thriving during stress: a randomized clinical trial comparing a brief web-based therapist-assisted acceptance-based behavioral intervention versus waitlist control for college students. Behav Ther 2018 Nov;49(6):889-903. [doi: 10.1016/j.beth.2018.05.009] [Medline: 30316488]

68. Flett J, Hayne H, Riordan B, Thompson L, Conner T. Mobile mindfulness meditation: a randomised controlled trial of the effect of two popular apps on mental health. Mindfulness 2018 Oct 31;10(5):863-876. [doi: 10.1007/S12671-018-1050-9]

69. Gaigg SB, Flaxman PE, McLaven G, Shah R, Bowler DM, Meyer B, et al. Self-guided mindfulness and cognitive behavioural practices reduce anxiety in autistic adults: a pilot 8-month waitlist-controlled trial of widely available online tools. Autism 2020 May;24(4):867-883 [FREE Full text] [doi: 10.1177/1362361320909184] [Medline: 32267168]

70. Garrison KA, Pal P, O'Malley SS, Pittman BP, Gueorguieva R, Rojiani R, et al. Craving to quit: a randomized controlled trial of smartphone app-based mindfulness training for smoking cessation. Nicotine Tob Res 2020 Mar 16;22(3):324-331 [FREE Full text] [doi: 10.1093/ntr/nty126] [Medline: 29917096]

71. Gili M, Castro A, García-Palacios A, Garcia-Campayo J, Mayoral-Cleries F, Botella C, et al. Efficacy of three low-intensity, internet-based psychological interventions for the treatment of depression in primary care: randomized controlled trial. $\mathbf{J}$ Med Internet Res 2020 Jun 05;22(6):e15845 [FREE Full text] [doi: 10.2196/15845] [Medline: 32501276]

72. Glück TM, Maercker A. A randomized controlled pilot study of a brief web-based mindfulness training. BMC Psychiatry 2011 Nov 08;11:175 [FREE Full text] [doi: 10.1186/1471-244X-11-175] [Medline: 22067058]

73. Gu J, Cavanagh K, Strauss C. Investigating the specific effects of an online mindfulness-based self-help intervention on stress and underlying mechanisms. Mindfulness (N Y) 2018;9(4):1245-1257 [FREE Full text] [doi: 10.1007/s12671-017-0867-y] [Medline: 30100935]

74. Hearn JH, Finlay KA. Internet-delivered mindfulness for people with depression and chronic pain following spinal cord injury: a randomized, controlled feasibility trial. Spinal Cord 2018 Aug;56(8):750-761. [doi: 10.1038/s41393-018-0090-2] [Medline: 29581519] 
75. Hearn JH, Cotter I, Finlay KA. Efficacy of internet-delivered mindfulness for improving depression in caregivers of people with spinal cord injuries and chronic neuropathic pain: a randomized controlled feasibility trial. Arch Phys Med Rehabil 2019 Jan;100(1):17-25. [doi: 10.1016/j.apmr.2018.08.182] [Medline: 30268806]

76. Henriksson J, Wasara E, Rönnlund M. Effects of eight-week-web-based mindfulness training on pain intensity, pain acceptance, and life satisfaction in individuals with chronic pain. Psychol Rep 2016 Dec;119(3):586-607. [doi: 10.1177/0033294116675086] [Medline: 27780873]

77. Hesser H, Gustafsson T, Lundén C, Henrikson O, Fattahi K, Johnsson E, et al. A randomized controlled trial of internet-delivered cognitive behavior therapy and acceptance and commitment therapy in the treatment of tinnitus. J Consult Clin Psychol 2012 Aug;80(4):649-661. [doi: 10.1037/a0027021] [Medline: 22250855]

78. Hoffmann D, Rask CU, Hedman-Lagerlöf EP, Jensen JS, Frostholm L. Efficacy of internet-delivered acceptance and commitment therapy for severe health anxiety: results from a randomized, controlled trial. Psychol Med 2020 May 14:1-11. [doi: 10.1017/S0033291720001312] [Medline: 32404226]

79. Howells A, Ivtzan I, Eiroa-Orosa FJ. Putting the 'app' in happiness: a randomised controlled trial of a smartphone-based mindfulness intervention to enhance wellbeing. J Happiness Stud 2014 Oct 29;17(1):163-185. [doi: 10.1007/s10902-014-9589-1]

80. Ivtzan I, Young T, Lee H, Lomas T, Daukantaitė D, Kjell O. Mindfulness based flourishing program: a cross-cultural study of Hong Kong Chinese and British participants. J Happiness Stud 2017 Sep 13;19(8):2205-2223. [doi: 10.1007/s10902-017-9919-1]

81. Jelinek L, Arlt SD, Moritz SC, Schröder J, Westermann S, Cludius B. Brief web-based intervention for depression: randomized controlled trial on behavioral activation. J Med Internet Res 2020 Mar 26;22(3):e15312 [FREE Full text] [doi: 10.2196/15312] [Medline: $\underline{32213470]}$

82. Khazaeili M, Hajebi M, Mohamadkhani P, Mirzahoseini H. The effectiveness of mindfulness-based intervention on anxiety, depression and burden of caregivers of multiple sclerosis patients through web conferencing. Pract Clin Psychol 2019 Jan 30:21-32. [doi: 10.32598/jpcp.7.1.21]

83. Köhle N, Drossaert CH, Klooster PM, Schreurs KM, Hagedoorn M, Van Uden-Kraan CF, et al. Web-based self-help intervention for partners of cancer patients based on acceptance and commitment therapy and self-compassion training: a randomized controlled trial with automated versus personal feedback. Support Care Cancer 2021 Feb 19:-. [doi: 10.1007/s00520-021-06051-w] [Medline: 33608762]

84. Krieger T, Reber F, von Glutz B, Urech A, Moser CT, Schulz A, et al. An internet-based compassion-focused intervention for increased self-criticism: a randomized controlled trial. Behav Ther 2019 Mar;50(2):430-445. [doi: 10.1016/j.beth.2018.08.003] [Medline: 30824257]

85. Krusche A, Dymond M, Murphy SE, Crane C. Mindfulness for pregnancy: a randomised controlled study of online mindfulness during pregnancy. Midwifery 2018 Oct;65:51-57. [doi: 10.1016/j.midw.2018.07.005] [Medline: $\underline{30099285]}$

86. Kubo A, Kurtovich E, McGinnis M, Aghaee S, Altschuler A, Quesenberry C, et al. A randomized controlled trial of mhealth mindfulness intervention for cancer patients and informal cancer caregivers: a feasibility study within an integrated health care delivery system. Integr Cancer Ther 2019;18:1534735419850634 [FREE Full text] [doi: 10.1177/1534735419850634] [Medline: 31092044]

87. Kvillemo P, Brandberg Y, Bränström R. Feasibility and outcomes of an internet-based mindfulness training program: a pilot randomized controlled trial. JMIR Ment Health 2016 Jul 22;3(3):e33 [FREE Full text] [doi: 10.2196/mental.5457] [Medline: 27450466]

88. Lappalainen P, Langrial S, Oinas-Kukkonen H, Tolvanen A, Lappalainen R. Web-based acceptance and commitment therapy for depressive symptoms with minimal support: a randomized controlled trial. Behav Modif 2015 Nov;39(6):805-834. [doi: 10.1177/0145445515598142] [Medline: 26253644]

89. Lee D, Kang DH, Ha NH, Oh CY, Lee U, Kang SW. Effects of an online mind-body training program on the default mode network: an EEG functional connectivity study. Sci Rep 2018 Nov 16;8(1):16935 [FREE Full text] [doi: 10.1038/s41598-018-34947-x] [Medline: 30446714]

90. Levin ME, Pistorello J, Seeley JR, Hayes SC. Feasibility of a prototype web-based acceptance and commitment therapy prevention program for college students. J Am Coll Health 2014;62(1):20-30 [FREE Full text] [doi: 10.1080/07448481.2013.843533] [Medline: 24313693]

91. Levin ME, Haeger JA, Pierce BG, Twohig MP. Web-based acceptance and commitment therapy for mental health problems in college students: a randomized controlled trial. Behav Modif 2017 Jan 01;41(1):141-162. [doi: 10.1177/0145445516659645] [Medline: 27440189]

92. Levin ME, Navarro C, Cruz RA, Haeger J. Comparing in-the-moment skill coaching effects from tailored versus non-tailored acceptance and commitment therapy mobile apps in a non-clinical sample. Cogn Behav Ther 2019 May;48(3):200-216. [doi: 10.1080/16506073.2018.1503706] [Medline: 30117784]

93. Lilly M, Calhoun R, Painter I, Beaton R, Stangenes S, Revere D, et al. Destress 9-1-1-an online mindfulness-based intervention in reducing stress among emergency medical dispatchers: a randomised controlled trial. Occup Environ Med 2019 Oct;76(10):705-711. [doi: 10.1136/oemed-2018-105598] [Medline: 31138676] 
94. Lin J, Paganini S, Sander L, Lüking M, Ebert DD, Buhrman M, et al. An internet-based intervention for chronic pain. Dtsch Arztebl Int 2017 Oct 13;114(41):681-688 [FREE Full text] [doi: 10.3238/arztebl.2017.0681] [Medline: 29082858]

95. Ma Y, She Z, Siu AF, Zeng X, Liu X. Effectiveness of online mindfulness-based interventions on psychological distress and the mediating role of emotion regulation. Front Psychol 2018;9:2090 [FREE Full text] [doi: 10.3389/fpsyg.2018.02090] [Medline: $\underline{30429816}$ ]

96. Mak WW, Chan AT, Cheung EY, Lin CL, Ngai KC. Enhancing Web-based mindfulness training for mental health promotion with the health action process approach: randomized controlled trial. J Med Internet Res 2015 Jan 19;17(1):e8 [FREE Full text] [doi: 10.2196/jmir.3746] [Medline: 25599904]

97. Messer D, Horan JJ, Larkey LK, Shanholtz CE. Effects of internet training in mindfulness meditation on variables related to cancer recovery. Mindfulness 2019 Jun 4;10(10):2143-2151. [doi: 10.1007/s12671-019-01182-y]

98. Molander P, Hesser H, Weineland S, Bergwall K, Buck S, Jäder Malmlöf J, et al. Internet-based acceptance and commitment therapy for psychological distress experienced by people with hearing problems: a pilot randomized controlled trial. Cogn Behav Ther 2018 Mar;47(2):169-184. [doi: 10.1080/16506073.2017.1365929] [Medline: 28895787]

99. Morledge TJ, Allexandre D, Fox E, Fu AZ, Higashi MK, Kruzikas DT, et al. Feasibility of an online mindfulness program for stress management--a randomized, controlled trial. Ann Behav Med 2013 Oct;46(2):137-148 [FREE Full text] [doi: 10.1007/s12160-013-9490-x] [Medline: 23632913]

100. Nadler R, Carswell JJ, Minda JP. Online mindfulness training increases well-being, trait emotional intelligence, and workplace competency ratings: a randomized waitlist-controlled trial. Front Psychol 2020;11:255 [FREE Full text] [doi: 10.3389/fpsyg.2020.00255] [Medline: 32153468]

101. Nguyen-Feng VN, Frazier PA, Greer CS, Meredith L, Howard K, Paulsen J. Testing the efficacy of three brief web-based interventions for reducing distress among interpersonal violence survivors. Transl Issues Psychol Sci 2016;2(4):439-448. [doi: $10.1037 / \mathrm{tps} 0000099]$

102. Nguyen-Feng VN, Greer CS, Frazier P. Using online interventions to deliver college student mental health resources: evidence from randomized clinical trials. Psychol Serv 2017 Nov;14(4):481-489. [doi: 10.1037/ser0000154] [Medline: 29120206]

103. Nissen ER, O'Connor M, Kaldo V, Højris I, Borre M, Zachariae R, et al. Internet-delivered mindfulness-based cognitive therapy for anxiety and depression in cancer survivors: a randomized controlled trial. Psychooncology 2020 Jan;29(1):68-75 [FREE Full text] [doi: 10.1002/pon.5237] [Medline: 31600414]

104. Noone C, Hogan MJ. A randomised active-controlled trial to examine the effects of an online mindfulness intervention on executive control, critical thinking and key thinking dispositions in a university student sample. BMC Psychol 2018 Apr 05;6(1):13 [FREE Full text] [doi: 10.1186/s40359-018-0226-3] [Medline: 29622047]

105. O'Driscoll M, Byrne S, Byrne H, Lambert S, Sahm LJ. An online mindfulness-based intervention for undergraduate pharmacy students: results of a mixed-methods feasibility study. Curr Pharm Teach Learn 2019 Sep;11(9):858-875. [doi: 10.1016/j.cptl.2019.05.013] [Medline: 31570123]

106. Potharst ES, Boekhorst MG, Cuijlits I, van Broekhoven KE, Jacobs A, Spek V, et al. A randomized control trial evaluating an online mindful parenting training for mothers with elevated parental stress. Front Psychol 2019;10:1550 [FREE Full text] [doi: 10.3389/fpsyg.2019.01550] [Medline: 31379646]

107. Puzia ME, Huberty J, Eckert R, Larkey L, M R R. Associations between global mental health and response to an app-based meditation intervention in myeloproliferative neoplasm patients. Integr Cancer Ther 2020;19:1534735420927780 [FREE Full text] [doi: 10.1177/1534735420927780] [Medline: 32564631]

108. Ritvo P, Ahmad F, Morr C, Pirbaglou M, Moineddin R, Team M. A mindfulness-based intervention for student depression, anxiety, and stress: randomized controlled trial. JMIR Ment Health 2021 Jan 11;8(1):e23491 [FREE Full text] [doi: 10.2196/23491] [Medline: 33264098 ]

109. Räsänen P, Lappalainen P, Muotka J, Tolvanen A, Lappalainen R. An online guided ACT intervention for enhancing the psychological wellbeing of university students: a randomized controlled clinical trial. Behav Res Ther 2016 Mar;78:30-42. [doi: 10.1016/j.brat.2016.01.001] [Medline: 26848517]

110. Rosen KD, Paniagua SM, Kazanis WJ, Jones SC, Potter JS. Quality of life among women diagnosed with breast cancer: a randomized waitlist controlled trial of commercially available mobile app-delivered mindfulness training. Psychooncology 2018 Aug;27(8):2023-2030. [doi: 10.1002/pon.4764] [Medline: 29766596]

111. Russell L, Ugalde A, Orellana L, Milne D, Krishnasamy M, Chambers R, et al. A pilot randomised controlled trial of an online mindfulness-based program for people diagnosed with melanoma. Support Care Cancer 2019 Jul;27(7):2735-2746. [doi: 10.1007/s00520-018-4574-6] [Medline: 30506103]

112. Sagon AL, Danitz SB, Suvak MK, Orsillo SK. The mindful way through the semester: evaluating the feasibility of delivering an acceptance-based behavioral program online. J Context Behav Sci 2018 Jul;9:36-44. [doi: 10.1016/j.jcbs.2018.06.004]

113. Sairanen E, Lappalainen R, Lappalainen P, Kaipainen K, Carlstedt F, Anclair M, et al. Effectiveness of a web-based Acceptance and Commitment Therapy intervention for wellbeing of parents whose children have chronic conditions: a randomized controlled trial. J Context Behav Sci 2019 Jul;13:94-102. [doi: 10.1016/J.JCBS.2019.07.004] 
114. Scott W, Chilcot J, Guildford B, Daly-Eichenhardt A, McCracken LM. Feasibility randomized-controlled trial of online Acceptance and Commitment Therapy for patients with complex chronic pain in the United Kingdom. Eur J Pain 2018 Apr 28:A. [doi: 10.1002/ejp.1236] [Medline: 29704880]

115. Shore R, Strauss C, Cavanagh K, Hayward M, Ellett L. A randomised controlled trial of a brief online mindfulness-based intervention on paranoia in a non-clinical sample. Mindfulness (N Y) 2018;9(1):294-302 [FREE Full text] [doi: 10.1007/s12671-017-0774-2] [Medline: 29387267]

116. Simister HD, Tkachuk GA, Shay BL, Vincent N, Pear JJ, Skrabek RQ. Randomized controlled trial of online acceptance and commitment therapy for fibromyalgia. J Pain 2018 Jul;19(7):741-753. [doi: 10.1016/j.jpain.2018.02.004] [Medline: 29481976]

117. Stjernswärd S, Hansson L. Effectiveness and usability of a web-based mindfulness intervention for families living with mental illness. Mindfulness (N Y) 2017;8(3):751-764 [FREE Full text] [doi: 10.1007/s12671-016-0653-2] [Medline: 28515801]

118. Tighe J, Shand F, Ridani R, Mackinnon A, De La Mata N, Christensen H. Ibobbly mobile health intervention for suicide prevention in Australian Indigenous youth: a pilot randomised controlled trial. BMJ Open 2017 Jan 27;7(1):e013518 [FREE Full text] [doi: 10.1136/bmjopen-2016-013518] [Medline: 28132007]

119. Trompetter HR, Bohlmeijer ET, Veehof MM, Schreurs KM. Internet-based guided self-help intervention for chronic pain based on Acceptance and Commitment Therapy: a randomized controlled trial. J Behav Med 2015 Feb;38(1):66-80. [doi: 10.1007/s10865-014-9579-0] [Medline: 24923259]

120. van Emmerik AA, Berings F, Lancee J. Efficacy of a mindfulness-based mobile application: a randomized waiting-list controlled trial. Mindfulness (N Y) 2018;9(1):187-198 [FREE Full text] [doi: 10.1007/s12671-017-0761-7] [Medline: 29387266]

121. Viskovich S, Pakenham KI. Pilot evaluation of a web-based acceptance and commitment therapy program to promote mental health skills in university students. J Clin Psychol 2018 Dec;74(12):2047-2069. [doi: 10.1002/jclp.22656] [Medline: 29962090]

122. Wahbeh H. Internet Mindfulness Meditation Intervention (IMMI) improves depression symptoms in older adults. Medicines (Basel) 2018 Nov 02;5(4):119 [FREE Full text] [doi: 10.3390/medicines5040119] [Medline: 30400211]

123. Wolever RQ, Bobinet KJ, McCabe K, Mackenzie ER, Fekete E, Kusnick CA, et al. Effective and viable mind-body stress reduction in the workplace: a randomized controlled trial. J Occup Health Psychol 2012 Apr;17(2):246-258. [doi: 10.1037/a0027278] [Medline: 22352291]

124. Yang E, Schamber E, Meyer RM, Gold JI. Happier Healers: randomized controlled trial of mobile mindfulness for stress management. J Altern Complement Med 2018 May;24(5):505-513. [doi: 10.1089/acm.2015.0301] [Medline: 29420050]

125. Zernicke KA, Campbell TS, Speca M, McCabe-Ruff K, Flowers S, Carlson LE. A randomized wait-list controlled trial of feasibility and efficacy of an online mindfulness-based cancer recovery program: the eTherapy for cancer applying mindfulness trial. Psychosom Med 2014 May;76(4):257-267. [doi: 10.1097/PSY.0000000000000053] [Medline: 24804884]

126. Lipsey MW, Wilson DB. The efficacy of psychological, educational, and behavioral treatment. Confirmation from meta-analysis. Am Psychol 1993 Dec;48(12):1181-1209. [doi: 10.1037//0003-066x.48.12.1181] [Medline: $\underline{\text { 8297057] }}$

127. Hedges LV, Vevea JL. Fixed- and random-effects models in meta-analysis. Psychol Methods 1998;3(4):486-504. [doi: 10.1037/1082-989x.3.4.486]

128. Nadler R, Carswell JJ, Minda JP. Online mindfulness training increases well-being, trait emotional intelligence, and workplace competency ratings: a randomized waitlist-controlled trial. Front Psychol 2020;11:255 [FREE Full text] [doi: 10.3389/fpsyg.2020.00255] [Medline: 32153468]

129. Hoffmann D, Rask CU, Hedman-Lagerlöf E, Jensen JS, Frostholm L. Efficacy of internet-delivered acceptance and commitment therapy for severe health anxiety: results from a randomized, controlled trial. Psychol Med 2020 May 14:1-11. [doi: 10.1017/S0033291720001312] [Medline: 32404226]

130. Levin M, Haeger J, Cruz R. Tailoring acceptance and commitment therapy skill coaching in the moment through smartphones: results from a randomized controlled trial. Mindfulness $2018 \mathrm{Jul}$ 21;10(4):689-699. [doi: 10.1007/s12671-018-1004-2]

131. Henriksson J, Wasara E, Rönnlund M. Effects of eight-week-web-based mindfulness training on pain intensity, pain acceptance, and life satisfaction in individuals with chronic pain. Psychol Rep 2016 Dec;119(3):586-607. [doi: 10.1177/0033294116675086] [Medline: 27780873]

132. Krusche A, Dymond M, Murphy SE, Crane C. Mindfulness for pregnancy: a randomised controlled study of online mindfulness during pregnancy. Midwifery 2018 Oct;65:51-57. [doi: 10.1016/j.midw.2018.07.005] [Medline: 30099285]

133. Duval S, Tweedie R. Trim and fill: A simple funnel-plot-based method of testing and adjusting for publication bias in meta-analysis. Biometrics 2000 Jun;56(2):455-463. [doi: 10.1111/j.0006-341x.2000.00455.x] [Medline: 10877304]

134. Carpenter JK, Andrews LA, Witcraft SM, Powers MB, Smits JA, Hofmann SG. Cognitive behavioral therapy for anxiety and related disorders: a meta-analysis of randomized placebo-controlled trials. Depress Anxiety 2018 Jun;35(6):502-514 [FREE Full text] [doi: 10.1002/da.22728] [Medline: 29451967]

135. Santoft F, Axelsson E, Öst L, Hedman-Lagerlöf M, Fust J, Hedman-Lagerlöf E. Cognitive behaviour therapy for depression in primary care: systematic review and meta-analysis. Psychol Med 2019 Jun;49(8):1266-1274. [doi:

10.1017/S0033291718004208] [Medline: 30688184] 
136. Kelders SM, Howard M. Opportunities of technology to promote health and well-being. In: van Gemert-Pijnen L, Kelders SM, Kip H, Sanderman R, editors. eHealth Research, Theory and Development. Oxfordshire, United Kingdom: Routledge; 2018.

137. Massoudi B, Holvast F, Bockting C, Burger H, Blanker M. The effectiveness and cost-effectiveness of e-health interventions for depression and anxiety in primary care: a systematic review and meta-analysis. J Affect Disord 2019 Feb 15;245:728-743 [FREE Full text] [doi: 10.1016/j.jad.2018.11.050] [Medline: 30447572]

138. Jones DJ, Anton M, Gonzalez M, Honeycutt A, Khavjou O, Forehand R, et al. Incorporating mobile phone technologies to expand evidence-based care. Cogn Behav Pract 2015 Aug 01;22(3):281-290 [FREE Full text] [doi: 10.1016/j.cbpra.2014.06.002] [Medline: 26213458]

139. Williams GC, Lynch M, Glasgow RE. Computer-assisted intervention improves patient-centered diabetes care by increasing autonomy support. Health Psychol 2007 Nov;26(6):728-734. [doi: 10.1037/0278-6133.26.6.728] [Medline: 18020845]

140. Lippmann M, Laudel H, Heinzle M, Narciss S. Relating instructional design components to the effectiveness of internet-based mindfulness interventions: a critical interpretive synthesis. J Med Internet Res 2019 Nov 27;21(11):e12497 [FREE Full text] [doi: 10.2196/12497] [Medline: $\underline{31774413}$ ]

141. Silvia PJ, Cotter KN. What are daily life methods? In: Researching Daily Life: A Guide to Experience Sampling and Daily Diary Methods. Washington, D.C., United States: American Psychological Association; 2021:3-15.

142. Keyes CL. The mental health continuum: from languishing to flourishing in life. J Health Soc Behav 2002 Jun;43(2):207-222. [Medline: 12096700]

143. Chakhssi F, Kraiss JT, Sommers-Spijkerman M, Bohlmeijer ET. The effect of positive psychology interventions on well-being and distress in clinical samples with psychiatric or somatic disorders: a systematic review and meta-analysis. BMC Psychiatry 2018 Jun 27;18(1):211 [ [FREE Full text] [doi: 10.1186/s12888-018-1739-2] [Medline: 29945603]

144. Keyes CLM. Mental illness and/or mental health? Investigating axioms of the complete state model of health. J Consult Clin Psychol 2005 Jun;73(3):539-548. [doi: 10.1037/0022-006X.73.3.539] [Medline: 15982151]

145. Weich S, Brugha T, King M, McManus S, Bebbington P, Jenkins R, et al. Mental well-being and mental illness: findings from the Adult Psychiatric Morbidity Survey for England 2007. Br J Psychiatry 2011 Jul;199(1):23-28. [doi: 10.1192/bjp.bp.111.091496] [Medline: 21719878]

146. Lamers SM, Westerhof GJ, Bohlmeijer ET, ten Klooster PM, Keyes CL. Evaluating the psychometric properties of the Mental Health Continuum-Short Form (MHC-SF). J Clin Psychol 2011 Jan;67(1):99-110. [doi: 10.1002/jclp.20741] [Medline: 20973032]

147. Lamers SM, Westerhof GJ, Glas CA, Bohlmeijer ET. The bidirectional relation between positive mental health and psychopathology in a longitudinal representative panel study. J Posit Psychol 2015 May 27;10(6):553-560. [doi: $10.1080 / 17439760.2015 .1015156]$

148. Keyes CL, Dhingra SS, Simoes EJ. Change in level of positive mental health as a predictor of future risk of mental illness. Am J Public Health 2010 Dec;100(12):2366-2371. [doi: 10.2105/AJPH.2010.192245] [Medline: 20966364]

149. Wood AM, Joseph S. The absence of positive psychological (eudemonic) well-being as a risk factor for depression: a ten year cohort study. J Affect Disord 2010 May;122(3):213-217. [doi: 10.1016/j.jad.2009.06.032] [Medline: 19706357]

150. A-Tjak JG, Davis ML, Morina N, Powers MB, Smits JA, Emmelkamp PM. A meta-analysis of the efficacy of acceptance and commitment therapy for clinically relevant mental and physical health problems. Psychother Psychosom 2015 Dec 24;84(1):30-36. [doi: 10.1159/000365764] [Medline: 25547522]

151. Brown M, Glendenning A, Hoon AE, John A. Effectiveness of web-delivered acceptance and commitment therapy in relation to mental health and well-being: a systematic review and meta-analysis. J Med Internet Res 2016 Aug 24;18(8):e221 [FREE Full text] [doi: 10.2196/jmir.6200] [Medline: 27558740]

152. Thompson E, Destree L, Albertella L, Fontenelle L. Internet-based acceptance and commitment therapy: a transdiagnostic systematic review and meta-analysis for mental health outcomes. Behav Ther 2021 Mar;52(2):492-507 [FREE Full text] [doi: 10.1016/j.beth.2020.07.002] [Medline: 33622516]

153. Cuijpers P, Kleiboer A, Karyotaki E, Riper H. Internet and mobile interventions for depression: opportunities and challenges. Depress Anxiety 2017 Jul;34(7):596-602. [doi: 10.1002/da.22641] [Medline: 28471479]

154. Cuijpers P. Four decades of outcome research on psychotherapies for adult depression: an overview of a series of meta-analyses. Can Psychol 2017;58(1):7-19. [doi: 10.1037/cap0000096]

155. Barth J, Munder T, Gerger H, Nüesch E, Trelle S, Znoj H, et al. Comparative efficacy of seven psychotherapeutic interventions for patients with depression: a network meta-analysis. PLoS Med 2013;10(5):e1001454 [FREE Full text] [doi: 10.1371/journal.pmed.1001454] [Medline: 23723742]

156. Beatty L, Binnion C. A systematic review of predictors of, and reasons for, adherence to online psychological interventions. Int J Behav Med 2016 Dec;23(6):776-794. [doi: 10.1007/s12529-016-9556-9] [Medline: 26957109]

157. Eysenbach G. The law of attrition. J Med Internet Res 2005;7(1):e11 [FREE Full text] [doi: 10.2196/jmir.7.1.e11] [Medline: 15829473]

158. Sieverink F, Kelders SM, van Gemert-Pijnen JE. Clarifying the concept of adherence to eHealth technology: systematic review on when usage becomes adherence. J Med Internet Res 2017 Dec 06;19(12):e402 [FREE Full text] [doi: 10.2196/jmir.8578] [Medline: 29212630] 
159. Parsons CE, Crane C, Parsons LJ, Fjorback LO, Kuyken W. Home practice in Mindfulness-Based Cognitive Therapy and Mindfulness-Based Stress Reduction: a systematic review and meta-analysis of participants' mindfulness practice and its association with outcomes. Behav Res Ther 2017 Aug;95:29-41 [FREE Full text] [doi: 10.1016/j.brat.2017.05.004] [Medline: $\underline{28527330]}$

\title{
Abbreviations
}

ACT: Acceptance and Commitment Therapy

MBCT: Mindfulness-Based Cognitive Therapy

MBI: mindfulness-based intervention

MBSR: Mindfulness-Based Stress Reduction

PRISMA: Preferred Reporting Items for Systematic Reviews and Meta-Analyses

RCT: randomized controlled trial

\author{
Edited by L Buis, G Eysenbach; submitted 23.02.21; peer-reviewed by H Wahbeh; comments to author 17.03.21; revised version \\ received 05.05.21; accepted 16.05.21; published 19.07.21 \\ Please cite as: \\ Sommers-Spijkerman M, Austin J, Bohlmeijer E, Pots W \\ New Evidence in the Booming Field of Online Mindfulness: An Updated Meta-analysis of Randomized Controlled Trials \\ JMIR Ment Health 2021;8(7):e28168 \\ URL: https://mental.jmir.org/2021/7/e28168 \\ doi: $10.2196 / 28168$ \\ PMID: 34279240
}

CMarion Sommers-Spijkerman, Judith Austin, Ernst Bohlmeijer, Wendy Pots. Originally published in JMIR Mental Health (https://mental.jmir.org), 19.07.2021. This is an open-access article distributed under the terms of the Creative Commons Attribution License (https://creativecommons.org/licenses/by/4.0/), which permits unrestricted use, distribution, and reproduction in any medium, provided the original work, first published in JMIR Mental Health, is properly cited. The complete bibliographic information, a link to the original publication on https://mental.jmir.org/, as well as this copyright and license information must be included. 